\title{
GLOBALIZATION AND THE GENDER WAGE GAP
}

\author{
Remco H. Oostendorp
}

Free University Amsterdam

Amsterdam Institute for International Development

roostendorp@,feweb.vu.nl

World Bank Policy Research Working Paper 3256, April 2004

The Policy Research Working Paper Series disseminates the findings of work in progress to encourage the exchange of ideas about development issues. An objective of the series is to get the findings out quickly, even if the presentations are less than fully polished. The papers carry the names of the authors and should be cited accordingly. The findings, interpretations, and conclusions expressed in this paper are entirely those of the authors. They do not necessarily represent the view of the World Bank, its Executive Directors, or the countries they represent. Policy Research Working Papers are available online at http://econ.worldbank.org. 
Globalization and the Gender Wage Gap

\section{ABSTRACT}

There are several theoretical reasons why globalization will have a narrowing as well as widening effect on the gender wage gap, but little is known about the actual impact, except for a number of country studies. This study provides a cross-country study of the impact of globalization on the occupational gender wage gap, based on the rarely used but most far-ranging survey of wages around the world, the ILO October Inquiry. This annual survey was started in 1924 and contains a wealth of information on wages and the gender wage gap. For the period 1983-99, there is information on the gender wage gap in 161 narrowly defined occupations in more than 80 countries around the world. This study finds the following: (i) the occupational gender wage gap appears to be narrowing with increases in GDP per capita; (ii) there is a significantly narrowing impact of trade and FDI net inflows on the occupational gender wage gap for low-skill occupations, both in poorer and richer countries, and for high-skill occupations in richer countries; (iii) there is no evidence of a narrowing impact of trade, but there is evidence of a widening impact of FDI net inflows on the high skill occupational gender wage gap in poorer countries; and (iv) wage-setting institutions have a strong impact on the occupational gender wage gap in richer countries.

Overall the study concludes that the occupational gender gap appears to fall with increasing economic development, trade and foreign investment, but not always. The lack of evidence of a narrowing impact of trade and evidence of a widening impact of FDI net inflows on the high-skill occupational gender gap in poorer countries show that globalization may not lower and in some instances may increase occupational gender wage gaps. This finding complements earlier studies documenting an increase in wage inequality after trade liberalization in a number of developing countries, possibly reflecting skill complementarities.

Remco H. Oostendorp

Free University Amsterdam

De Boelelaan 1105, Kamer 4A-23

1081 HV Amsterdam, The Netherlands

roostendorp@feweb.vu.nl 


\section{Introduction ${ }^{1}$}

There are several reasons why globalization will have a narrowing effect on the gender wage gap. First, according to neoclassical theory, globalization will lead to increasing competitive pressures, making it more costly for individuals and firms to discriminate (Becker 1971). Second, increasing trade will expand job opportunities with an increasing number of women being absorbed in export-oriented industries (Wood 1991; Anker 1998; Standing 1999; Cagatay and Berik 1991; Ozler 2000). However, the female share of labor may peak with increasing exports if the demand for the generally lower-skilled female labor first rises and subsequently falls again over time (Joekes 1995). Third, increasing trade will spur economic growth, with more investments in infrastructure and the availability and quality of public services. This, together with rising household incomes, will typically mean that gender disparities in human capital will fall with economic development, and therefore the gender wage gap as well (World Bank 2001).

However, globalization may also worsen the gender wage gap. First, standard trade theory predicts that trade will adversely affect the compensation paid to the relatively scarce factors of production in the economy. If female workers in developed economies tend to have lower skills than male workers, then female wages will be more adversely affected by increases in trade with developing countries than male workers. This skill effect would increase the gender wage gap. Of course the opposite is true for developing countries -their gender wage gap should fall with increases in trade. Second, globalization through increasing competition may weaken the bargaining power of workers, and especially female workers if they are disproportionally employed in sectors increasingly competing on the basis of "cheap" labor. If globalization means an increased ability of businesses to relocate all or some segments of their production across national borders, this will put a downward pressure on the wages of workers in the affected industries (UN 1999). Third, there are complicated linkages between the traded sectors

1 I would like to thank participants at seminars at The World Bank in Washington D.C. and Jakarta, as well as at the Institute of Southeast Asian Studies, for useful comments. I am particularly grateful to Andy Mason, Susan Razzaz, Aart Kraay, Nayantara Mukerji and Yana Rodgers for constructive comments. This research has been financially supported by the Bank-Netherlands Partnership Program's Economic Policy 
and other sectors in the market economy, as well as between the market economy and the unpaid household economy where women are the main workers (Fontana and Wood 2000). For instance, if trade leads to increasing occupational segregation, or a reduction in leisure time for female workers, women may be less motivated to pursue a life-long career, thereby increasing the gender gap.

Only a few country studies have looked at the impact of trade on the gender wage gap. Black and Brainard (2002) find that increased competition through trade did contribute to the relative improvement in female wages in concentrated relative to competitive industries in the United States between 1976 and 1993, suggesting that trade may benefit women by reducing firms' ability to discriminate. García-Cuéllar (2000) and Artecona and Cunningham (2002), using data on Mexican wages, find that the gender gap decreased more in industries that were more affected by trade (in terms of import licenses' reductions or import penetration) than in other industries. Berik, van der Meulen Rodgers and Zveglich (2004) analyze the impact of competition from international trade on the gender wage gap in Taiwan and South Korea between 1980 and 1999, and find that greater international competition in concentrated sectors was associated with larger gender wage gaps, contradicting Becker's theory. ${ }^{2}$ Fontana and Wood (2000) use a computable general equilibrium model for Bangladesh to simulate the gendered effects of changes in trade policies and capital flows. They find that the gender wage gap narrows with a rise in foreign capital inflows and an increase in exports, as long as exports are female-led.

This study analyzes the rarely-used ILO October Inquiry to do a cross-country study of the impact of globalization on the gender wage gap, and provides evidence on the impact of trade and FDI net inflows across many countries. The ILO October Inquiry is the most far-ranging survey of wages around the world, and contains information on the gender wage gap in 161 narrowly-defined occupations in more than 80 countries for

and Gender Initiative Any responsibility for remaining errors that remain rests with the author. 2 There are also a number of country studies looking at the impact of market structure on the gender gap. Although these studies do not focus on trade, they are suggestive in the sense that trade can have an impact on the gender wage gap through changes in market structure. Black and Strahan (2001) have shown that deregulation in the banking industry in the United States was associated with a significant improvement in the relative wages of women. Hellerstein et al. (2002) found that enterprises that have weak market power tend to pay women and men more nearly equal wages, while firms that are large relative to the market tend to discriminate. 
1983-99. Although the pre-1983 ILO October Inquiry contains data on male and female wages for 12 occupations, the analysis in this study focuses on the 1983-99 data..

The main conclusions of the paper are as follows. First, the occupational gender gap appears to be narrowing with increases in GDP per capita,. Second, there is a significantly narrowing impact of trade and FDI net inflows on the occupational gender gap for low-skill occupations, both in poorer and richer countries, and for high-skill occupations in richer countries. Third, there is no evidence of a narrowing impact of trade and evidence of a widening impact of FDI net inflows on the high-skill occupational gender gap for poorer countries, possibly reflecting skill complementarities. And finally, wage-setting institutions have a strong impact on the occupational gender wage gap in richer countries.

\section{Measuring the Occupational Gender Wage Gap Using the ILO October Inquiry}

Since 1924 the ILO has conducted an "October Inquiry" on pay by occupation across the world. The ILO sends a questionnaire to national governments asking for wages in detailed occupations, within particular industries. ${ }^{3}$ To assure comparability of occupational definitions across the countries, the ILO specifies in great detail the work involved in each occupation. To get a flavor of the specificity consider the following description of a clicker cutter in the footwear industry:

Clicker cutter (machine). Operates press machine which cuts out upper parts of footwear; lays material on the table of machine; selects cutting dies; arranges dies on material to cut it economically and avoid weaknesses; cuts out show part by lowering press onto dies; removes cut-out parts from material.

Or this (abbreviated) description of an accountant in a bank:

Accountant. Plans and administers accounting services and examines, analyses, interprets and evaluates accounting records for the purpose of giving advice on accountancy problems or preparing statements and installing or advising on systems of recording costs or other financial and budgetary data: ... keeps record of all taxes, fees,

3 Some occupations occur in multiple industries (such as 'labourer') and in that case the ILO has collected wage data for these occupations in each of the industries. 
etc. to be paid by the bank ...conducts financial investigations on suspected fraud ... prepares and certifies financial statements for presentation to the board of directors, executives, shareholders ...

Table 1 shows the coverage of the October Inquiry by occupation and country over time. In 1924 the survey gathered data on wages in 18 occupations in 15 countries. In ensuing years the ILO expanded the number of countries and occupations. Country coverage increases fairly steadily so that the 1983-99 Inquiry data files on which we focus had wage statistics for 158 countries in at least one year and wages for up to 76 countries in any given year. The number of occupations increased from 30 occupations in 1929 , to 41 in 1951, to 48 in 1953 , and then to 161 in $1983 .{ }^{4}$

With respect to gender, the ILO October Inquiry reported wages for male earners for the period 1924-1952. In 1953 it changed the observation unit to adult workers, but with a gender breakdown in reported pay for 6 occupations. In each of the years in the period 1954-1982 there was a gender breakdown for between 6 and 12 occupations. After 1982 the number of occupations was expanded to 161, and for most of these occupations a gender breakdown and therefore gender gap was reported in any year.

If each country contributed information on wages from a nationally representative survey based on ILO definitions, the October Inquiry would be the ideal source for comparing the pay of male and female workers across countries and occupations.

However the October Inquiry data fall short of being ideal. Indeed, the problems involved are such that the Inquiry is one of the least used sources of cross-country data in the world (see Freeman and Oostendorp 2000, 2002).

The main problem is that countries respond to the ILO's request for information often in inconsistent ways. Recorded wages are not directly comparable either between countries or in the same country over time, or between occupations in one country at a point in time. The recorded wages are non-comparable because countries report data from a variety of national sources rather than conducting special surveys to respond to the

\footnotetext{
4 Starting from 1983, the ILO actually asks for information on 159 occupations but it differentiates occupation 139, executives in the government into three sectors; national, regional or provincial, and local governments. The number of occupations was expanded over time by adding new occupations, while a few occupations were dropped. The definition of the individual occupations was changed in 1983 for the last time, but most pre-1983 occupations can be matched with the 1983-99 occupations. However because we only use the 1983-99 data there is no need to do this matching.
} 
ILO's request. Some countries, e.g. Honduras and the Philippines, report wages paid in an occupation from an establishment survey. Other countries, e.g. India, report legislated minimum wage rates for certain occupations. Still others, e.g. Germany, report minimum wage rates based on collective agreements on hourly, daily, weekly, or monthly wage rates, depending on the occupation. Moreover, data sources change over time. For example, up to 1985 the United States reported wage rates from trade unions and earnings from the Industry Wage Surveys. From 1986 to 1997, the United States reported median usual weekly earnings from the Current Population Survey. Since 1997, the United States has reported median wage rates from an employer-based survey. Some countries give male workers' wages in certain occupations. Others report both male and female workers' wages. Still others report female workers' wages in certain occupations. And so on.

Another problem is that countries do not report consistently from year to year. In the 1983-99 period, 158 countries reported wages in at least one year, but only five countries reported wages 17 times (i.e. every year), 40 reported 10-16 times, 51 reported 5-9 times, 43 reported 2-4 times, and 19 reported just once. Looking back across the years, in 1983, 56 countries reported wages; in 1985, 71 reported wages; in 1990, 72 reported; in 1992, 60 reported; in 1995, 76 reported; in 1997, 66 reported; and finally in 1999, 45 countries reported wages. The uneven pattern in reporting makes it tricky to conduct time-series and trend analyses. In addition, over time the ILO has asked for data on different numbers of occupations, which makes trend comparisons difficult, particularly those between the post-1983 period and earlier years. Moreover, some countries do not provide national data but report data from particular regions instead, e.g. major cities or urban areas.

A third problem relates to the concepts of wages used in the October Inquiry. Information is requested on average wage or salary rates and average regular gross earnings, together with the relevant hours of work, with respect to the month of October. The October Inquiry does not seek to cover all components of earnings (irregular bonuses, including such important payments as the annual or bi-annual bonuses paid in Japan and some other Asian countries, may represent a significant part of total gross earnings). Nor does it seek to obtain information on all supplementary labour costs. To 
the extent that employers' and employees' social contributions are often proportionate to wages, this will not affect estimates of relative wage structures in countries, but it will affect, and often underestimate, inter-country differences in labour costs or living standards.

A fourth problem is that even with the ILO's detailed specification of skills, the work performed in a given occupation can vary from one country to another. Even in one country, skills differ within the narrow ILO categories. The range of skills displayed by cooks employed in restaurants and hotels (one of the ILO's specified occupations) in the United Kingdom varies considerably, depending on the size of an establishment, the type of cuisine offered, and the number of stars in the guidebook. Such differences are likely to be even greater between countries. To the extent that differences in skills within occupations are associated with education, the workers in advanced industrialized countries are likely to be more skilled than those in less advanced, developing countries.

Finally, there is the problem of the quality of the data provided to the ILO. As already mentioned, countries send the ILO data obtained from a range of different sources: government agencies; collective agreements; legally determined scales, such as minimum wage rates; and surveys of varying quality. Approximately half the data are based on surveys, mostly enterprise surveys. There are potential quality problems with each of these sources, depending on the data-gathering process. At our request, the ILO's Bureau of Statistics has classified the various data sources into four quality groups, ranging from "not acceptable", "poor quality", "acceptable/good" to "excellent". The vast bulk of the data were rated as being in the "acceptable/good" category (52.6 per cent) or the "excellent" category (32.4 per cent), and 15\% was rated as "not acceptable" or "poor". The data of acceptable/good or excellent quality was further cleaned by the author and still another $16 \%$ of the observations were dropped. ${ }^{6}$

5 The quality assessment of the October Inquiry data was based on information available within the ILO on the data sources, consistency of the data (trend, regularity, consistency between wage rates and earnings, etc.), comparisons with other wage data received for publication in the Yearbook of Labour Statistics, and questions raised with countries and the types of replies received.

6 The time-series for each country/occupation pair was inspected, and observations that were clearly deviating from the time pattern were omitted. Entire occupation/year pairs were omitted if there was no pattern whatsoever. No cut-off point with respect to very low or very high reported wage gaps was imposed. Differences in gender gap across reported locations and gender differences in hours worked were taken into account. Sometimes whole countries were dropped because too many occupations had to be dropped, suggesting serious data problems. 
Table 2 provides a detailed description of the types of information contained in the resulting October Inquiry files for 1983 to 1999, the period on which we focus. Here we only report on countries that reported at least one gender breakdown in the period 1983-99. In total there were 83 countries which did report at least one gender breakdown during this period. Freeman and Oostendorp $(2000,2002)$ provide information on all countries available in the October Inquiry files, also for the countries which did not report any male-female breakdown.

Panel A gives information on the size of the sample. It shows the maximum conceivable observations that the Inquiry would contain if each country reported a female and male wage statistic for each occupation yearly: over 227,171 male-female wage pairs. $^{7}$ The actual number of observations is smaller, largely because in many years most countries do not report statistics. On average, countries report male-female wages for 6.7 years out of 17 possible years. As a result, 80,500 of the potential observations are missing, because various countries did not report data in particular years. Moreover, in the years when countries did report, they did not report data for every occupation. The main point is that there are 13,020 country-year-occupation cells with female-male wage data in the 1983-99 file.

There is a further complication. Many countries report more than one female-male wage pair for a single occupation. Some give hourly wage rates and average earnings. Other give female-male wages for different locations. Nearly half the observations (45 percent) contain multiple wage figures. Including multiple wages, there are 18,931 female-male wage pairs.

Panel B shows the frequency distribution of countries by the number of occupations they report; and the frequency distribution of occupations by the number of countries that report statistics on them. The distribution of countries by number of occupations shows that in most countries the gender breakdown has been reported for less than 50 observations. In 17 countries the female-male wage has been reported for less than 5 occupations, while 13 countries report between 5 and 9 female-male wages. These numbers show that in many countries there are not enough occupations with

7 The maximum is the multiplicand of the number of countries (83) times the number of occupations (161) times the number of years (17). 
female-male wage data to get a good measure of the overall gender wage gap structure within a country. The distribution of occupations by country shows that there are femalemale wage data for 66 occupations in at least 20 countries, and for 18 occupations in at least 30 countries. This means that we can contrast the gender wage gap in these occupations around the world.

Panel $\mathrm{C}$ shows the various ways in which countries report female-male wages. Many countries report wage rates from employer surveys or collective agreements or legislated pay schedules. Others report earnings, some from household surveys but mostly from employer surveys. In total about half the observations are reported in wage rates, and the other half in earnings. Most give statistics in the form of means ${ }^{8}$, but some report minimum wage rates, maximum wage rates, prevailing wages, or medium wages. The period to which the pay refers also varies. The most common period is the month, followed by the week and hour, but some countries report daily, annual or forthnightly rates for some occupations.

How can we make valid comparisons of the gender wage gap across countries, occupations, and years if the data are available in such a heterogeneous format? In Freeman and Oostendorp $(2000,2002)$ a standardization procedure was developed to put the Inquiry data into a form that researchers can readily use, transforming each observation, however reported, into a standard rate based on the most common form of data in the Inquiry - monthly average wages for male workers. ${ }^{9}$ Here we use a similar procedure to standardize the gender wage differentials across countries, occupations, and years. We choose to standardize all gender wage differentials into average hourly earnings differentials, because earnings are a better measure of total compensation and only slightly less frequently reported than wages in our data set. Instead of standardizing the gender wage differentials, it would also be possible to standardize the wages for female and male workers first, and then use the standardized female and male wages to analyze the standardized gender wage differentials (or more accurately "the gender

8 In a few cases the wages are in the form of ranges. We found the midpoint of the range and report it as the wage for the category.

9 The standardization procedure involves two steps. In the first step dimensional analysis is used to convert annual, weekly, and forthnightly wages into monthly wages while hours of work data (if available) are used to convert hourly and daily wages into monthly wages. In the second step a regression analysis is applied to correct for the remaining differences in pay, averaging, and period concepts. 
standardized wage differentials"). Standardizing female and male wages separately is less efficient, however, because there are almost no gender differences in reported pay, averaging, and period concepts within occupations, so there is no need to adjust for these concepts within occupations. The only adjustments necessary are those to correct for differences in pay, averaging, and period concepts across occupations, and this what is what we have done. ${ }^{10}$

We have limited the heterogeneity of the data by limiting the pay concept to average, minimum, prevailing and median rates (excluding the maximum and 'other' rates). The 'average' pay concept is included because it is the preferred pay concept measuring the compensation of an average worker. We have also included the minimum and prevailing rates, however, because in the pre-1983 data this is a very common pay concept, and this will allow greater comparability over time. However we have excluded any observations where the reported minimum wage gender differential equals one -this is most likely a reflection of (non-discriminatory) statutory minimum rates rather than actual minimum rates. The median pay concept is only reported by the United States and has been retained to allow comparison with other research on US data.

The estimated adjustment factors are very small for the pay and period concepts. For the averaging concept there is a relatively large adjustment for minimum wages: the occupational gender wage gap is estimated to be $6 \%$ point higher for minimum wages as opposed to average wages. The estimated adjustment factors have been used to transform each observed gender wage gap into a gender wage gap for average hourly earnings. It is the latter standardized gender wage gap that we have used for the analysis. ${ }^{11}$

$10 \mathrm{We}$ did some preliminary analysis on standardized female and male wages, however, with few significant results. This is probably the result of loss of efficiency by standardizing female and male wages separately, rather than standardizing the wage differential directly.

11 Note that in the standardizing regressions we are assuming that the effect of the differences in concepts is the same across countries. If we had enough variation within the countries it would be possible to estimate country-specific adjustment factors. In our earlier standardization procedure for wages we have explored this issue by introducing country-specific adjustment factors (see Freeman and Oostendorp 2000). Because of lack of variation within countries, this could only be done for female-male wage differentials within countries, but not for differences in the pay, averaging and period concepts. Hence, when standardizing the gender wage gap itself, we do not have enough variation to estimate country-specific adjustment factors for the pay, averaging and period concepts. We have, however, also followed an intermediate route, and estimated adjustment factors specific for income levels. We found that allowing for income level-specific adjustment factors gives virtually the same results (available on request from the author). 


\section{The Occupational Gender Wage Gap around the World}

The ILO October Inquiry data allow us to look at the occupational gender wage gap, that is, the female-male wage difference within an occupation in a given country and year. Occupations have been narrowly defined, so in principle we have information on how much female engineers or clicker cutters earn in comparison to their male counterparts. It is important to point out that the ILO October Inquiry does not contain information on employment within these occupations, so we are unable to measure the average gender wage gap across workers. In principle it is even conceivable that the average gender wage gap across workers increases, while we observe a decline in gender wage gap in each of the occupations. ${ }^{12}$

Does this mean that the occupational gender wage gap is non-informative? Quite the contrary. Because it gives information on the gender wage gap within narrowly defined occupations, it is, in a way, more informative than the usual measures of the gender wage gap. Usual measures of the gender wage gap are the 'raw wage gap' and the 'unexplained wage gap'. The raw wage gap measures the female-male wage differentials for typically all employed workers or for broad occupational categories. Because female and male workers may be different from each other in terms of human capital (such as type of education, work experience), occupations, and hours worked, this measure will typically overstate the actual gender wage gap if one would control for these differences. The unexplained wage gap is the female-male wage differential that remains if gender differences in human capital are taken out (typically through a regression analysis). It can be thought of measuring gender discrimination, in the sense of indicating gender-specific prices for similar levels of human capital.

The occupational gender wage gap can be viewed as providing a direct measure of the unexplained wage gap, without relying on the availability of good human capital data and a regression method to control for gender differences in qualifications. Assuming that female and male workers in the narrowly defined occupations have similar skills, any

12 It has been suggested that sectoral employment weights from other data sources could be used to derive an aggregate gender wage gap. The problem is, however, that in many countries there are not enough observations with female-male wage data across sectors to get a good measure of the overall gender wage gap within a country (see section 2). 
wage differentials can be interpreted as direct evidence of wage discrimination. In so far as occupational skills are comparable across countries, the occupational gender wage gap can be compared across countries as well.

Table 3 presents the occupational gender wage gap by country for 1983-99, organized by the level of development. Here the occupational gender wage gap is measured as one minus the average ratio of the reported female and male wage for a given country and year across occupations. This definition implies that a gap of zero indicates no difference between female and male occupational wage, while a gap more than zero indicates that the female wage is lower than the comparable male wage.

In Table 3 for each country the year is selected for which most occupational gender wage gaps were reported (at least two occupational gaps). We report two occupational gender wage gap statistics, namely the unadjusted and the adjusted. The unadjusted occupational gender gap does not correct for differences in pay, averaging, and period concepts. ${ }^{13}$ The adjusted occupational gender wage gap corrects for differences in pay, averaging and period concepts. ${ }^{14}$ It indicates what the gender wage gap is for hourly average earnings.

First of all, there are relatively minor differences between the unadjusted and adjusted occupational gender wage gap, suggesting that the heterogeneity in reporting is not a major problem if one is looking at the gap between female and male wages. Secondly, the occupation gender wage gap is typically above zero, as female workers tend to earn less than male workers in the same occupations. The overall average occupational gender wage gap is 0.11 across all countries in the dataset. Looking across income groups, the richer countries actually appear to have a higher occupational gender wage gap. The average occupational gender wage gap is 0.13 ( 0.12 if adjusted) for the high income countries, and 0.04 (or 0.03 if adjusted) for the poor countries.

Recent empirical studies from 71 countries indicate that on average the gender raw wage gap is 0.23 in developed countries, and 0.27 in developing countries.

13 But dimensional analysis and the hours of work data have been used to calculate the gender gap on a hourly basis as much as possible.

14 More precisely, a regression has been estimated with dummies for the pay, averaging and period concept to adjust the occupational gender wage gap for different units. Lexicographic weighting has been used in case there are multiple standardized observations for a given country/year/occupation pair (see Freeman and Oostendorp 2000). 
Generally, only about 20 percent of the gender gap in earnings can be explained by observed differences in worker and job characteristics, leaving an unexplained gender wage gap of about 0.20 (World Bank 2001, pp.55-57). We find that the average occupational gender wage gap is 0.11 across countries. Unfortunately these figures are not completely comparable, as we are looking at the average occupational gender wage gap across countries, without taking into account employment patterns. They still suggest however a significant bias in the labor market treatment (discrimination) of women even within narrowly defined occupations.

\section{Occupational gender wage gap by level of economic development}

Does the occupational gender wage gap become larger or smaller with economic development? Figure 1 shows the adjusted occupational gender wage gap for 54 countries by the level of economic development, measured as the logarithm of GDP per capita (in constant 1995 US \$). For each country the year is selected for which most occupational gender wage gaps were reported (at least two occupational gaps). There is a positive cross-section relationship between the occupational gender wage gap and the level of economic development. A positive relationship is surprising, as we would expect a negative relationship between occupational gender wage gap and the level of economic development, given that gender disparities in human capital tend to fall with economic development (World Bank 2001).

Countries report different occupations and this may be a reason why there is a positive relationship between the occupational gender wage gap and the level of development. However, if we adjust the occupational gender wage gap for cross-country

differences in occupations reported, we still find a positive relationship. ${ }^{15}$ Also if we limit the analysis to the country/year pairs reporting at least five of the 20 most reported occupations, we also find a positive relationship between the level of economic development and the gender gap.

15 Specifically, we ran a regression of the occupational gender wage gap on occupation dummies and country by year dummies. The adjustment was done by subtracting the part of the occupational gender wage gap which could be explained by the occupation dummies. 
The above descriptive analysis suggests that if there is any relationship between the occupational gender wage gap and the level of development, it would be a positive one. However, the above analysis does not take into account other country differences which may affect the occupational gender wage gap and which are correlated with the level of development, such as wage-setting institutions and occupational segregation. In the regression analysis of section 4 we will attempt to control explicitly for these possible omitted country characteristics. We can already control for time-invariant country characteristics, however, by looking at within-country changes in the occupational gender wage gap. In order to do this, we have separated the sample in two groups, namely the top one-third countries which have seen the fastest growth rate in GDP per capita between the 1980s and 1990s, and the corresponding bottom one-third. The first group form the 'fast growth group', while the latter group forms the 'slow growth group'. Figure 2 shows the results. The average change in the occupational gender wage gap for the slow growth group is +0.04 (median change +0.02 ) between the 1980s and 1990s. The corresponding change is -0.02 (median change -0.01 ) for the fast growth group. Hence, the fast growth group has experienced a narrowing in the occupational gender wage gap, while the slow growth group experienced a widening. Also if we look at the number of positive and negative changes within each group the pattern is clear. Six out of eight countries in the slow growth group experienced an increase in the occupational gender wage gap, while six out of eight countries in the fast growth group experienced a decrease.

The occupational gender wage gap in globalizing countries

In the introduction we discussed different theories about the impact of trade on the gender gap. These theories often have implications for the gender wage gap across occupations or skill levels but not for the gender wage gap within occupations or skill levels. For instance, standard trade theory predicts that the compensation paid to the relatively scarce factors of production will fall, implying that both male and female wages will fall in occupations intensive in scarce factors. Similarly, any trade-induced fall in gender disparities in human capital will probably lead to more employed women in 
the higher skill occupations, but not necessarily a lower gender wage gap within occupations.

If we look at the gender wage gap within occupations, we would expect the impact of trade to be a narrowing one. First, trade will lead to more competition and therefore less discrimination, as argued by Becker (1971). Second, increases in trade will drive up the relative demand for female labor because female labor supply tends to be more elastic than male labor supply, and because women are disproportionally represented in export-oriented sectors, at least in developing countries (Wood 1991). Hence, prima facie, we expect a negative relationship between globalization and the occupational gender wage gap.

Globalization can be measured along different dimensions, and here we look at trade as a percentage of GDP (in current prices) and the FDI net inflows as a percentage of GDP. Figures 3 and 4 show a negative cross-country relationship between these measures of globalization and the occupational gender wage gap. Similar results are found if trade is measured as a percentage of GDP in constant LCU. ${ }^{16}$ Hence, these results suggest that trade and FDI inflows lower the occupational gender wage gap.

Instead of looking at the cross-sectional pattern one can also look at the time series pattern, by comparing 'globalizing' countries with 'non-globalizers'. Dollar and Kraay (2001) compare the growth performance of countries with large increases in trade and significant declines in tariffs over the past 20 years with the growth performance of other countries. They used various definitions to label countries as 'globalizers'. The interesting question here is whether these globalizing countries have also seen the greatest decrease in the occupational gender wage gap, that is the greatest narrowing of female and male wages?

Unfortunately our data are quite limited with respect to the globalizers as defined by Dollar and Kraay. This is especially so because we need to know the change in the occupational gender wage gap between the 1980s and 1990s. The ILO October Inquiry provides only information on changes in the occupational gender wage gap for globalizers China and Peru. We therefore introduce a different breakdown, namely between the 'fast trade group' of countries and the 'slow trade group' of countries.

16 This is the measure used by Dollar and Kraay (2001). 
Countries are included in the fast trade group if they belong among the top one-third of countries who have seen the largest increase in trade (as a percentage of GDP in current prices). Countries in the bottom one-third are included in the slow trade group. The overlap between the fast trade and the fast growth groups is limited -only Hong Kong, Sri Lanka, and Mauritius belong to both groups. Figure 5 shows the results. The average change in the occupational gender wage gap for the slow trade group is +0.04 (median +0.02 ) between the 1980s and 1990s, and -0.05 (median -0.02) for the fast growth group. Among the fast trade group five out of seven countries have seen a decrease in the occupational gender wage gap, as against three out of eight among the slow trade group. This supports the cross-section finding that trade lowers the occupational gender wage gap. If trade is expressed as a percentage of GDP in constant LCU, then we find a similar pattern with the occupational gender wage gap increasing in the slow trade group and decreasing in the fast trade group. However, the opposite pattern is found if FDI net inflows as a percentage of GDP is used -the occupational gender wage gap has increased for the group of countries which have seen the largest increase in FDI net inflows, but fallen for the group of countries which have seen the smallest increases in FDI net inflows.

It is clear that the above descriptive analysis may suffer from occupational heterogeneity (specification bias), the omission of factors that may have caused the changes in the occupational gender wage gap (omitted variable bias), and feedback effects from the gender gap on economic development and trade (simultaneity bias). In the following section we therefore provide a more in-depth regression analysis of the impact of globalization on the gender gap, taking into account each of the above potential biases. 


\section{Does Globalization Reduce the Occupational Gender Wage Gap? A Regression}

Analysis

\section{Regression estimates of the impact of trade and FDI on the occupational gender gap}

In Table 4 we report the cross-section estimates (OLS) of the effect of per capita income and a number of trade and FDI variables on the occupational gender wage gap. In this and all the following regressions we have omitted Hong Kong, Singapore, Azerbaijan and Luxembourg, because they are untypical either in terms of trading volume or FDI net inflows. Also throughout the analysis we will include dummy variables for Cyprus, Japan and Korea, as it was found that the cross-section estimates were strongly affected by the inclusion of these high occupational gender wage gap countries.

We estimate the impact of GDP per capita, trade and FDI on the gender gap for 'poorer' as well as 'richer' countries. The low and lower middle income countries are classified as 'poorer countries' and the high and higher middle income countries as 'richer countries'. The impact of GDP per capita, trade and FDI may differ with the level of development, given that the gender gap varies across level of development (Table 3) and given possible non-linearities in the relationships between GDP per capita, trade and FDI and the gender wage gap.

The first row of Table 4 shows that there is a significant positive impact of GDP per capita on the gender wage gap in poorer countries. For richer countries the impact is either positive or negative, depending on the globalization measure used, but not significant. The positive cross-section correlation confirms what we have already seen in Figure 1, except that we now observe the relationship to be non-linear and to hold for the poorer countries in particular. A non-linear relationship suggests a gender-equivalent of the Kuznets curve, with first an increase in gender inequality (within occupations) and then a decrease. However, Figure 2 and time-series analysis discussed below (Table 9) suggest that there is no Kuznets curve at the country level and that the gender gap falls with economic development. This apparent discrepancy or 'puzzle' will be discussed more below. 
In the second to fifth rows of Table 4 we report the coefficients for the trade and FDI variables in the regressions on the gender wage gap. As measures we use aggregate trade (in current and constant prices) and FDI net inflows (in current prices) as a percentage of GDP. Also we use a measure of sectoral trade based on the World Bank Trade and Production Database which contains data on trade, production and tariffs for 67 developing and developed countries at the industry level over the period 1976-1999. ${ }^{17}$ Occupations within the ILO October Inquiry can be linked with the ISIC codes in the Trade and Production Database given that each occupation belongs to a specific sector (ILO 1995). The use of sectoral trade data allows us to exploit the more direct link between sectoral trade and the gender wage gap for occupations in a sector. On the other hand, the number of observations is strongly reduced as the Trade and Production Database is limited to the manufacturing industries. The different regressions have different numbers of observations because of this difference in availability.

The second to fifth rows of Table 4 show that the effect of trade is generally negative (although not always significant), that is, the gender wage gap tends to fall with the openness of the economy. This result confirms what we already have seen in Figure 3. For FDI net inflows we find a more ambiguous pattern, with a negative and a positive but insignificant effect for the poorer and richer countries respectively. The use of the Sachs-Warner measure of openness gives an insignificant result as well (not reported). The $\mathrm{R}^{2}$ is much lower for poorer countries, which may reflect greater measurement error in poorer countries and therefore heteroskedasticity. The standard errors are therefore corrected for clustering within country/occupation observations throughout the analysis.

Overall we can conclude that countries that trade more tend to have a lower occupational gender wage gap. In the following we will further investigate this basic result by analyzing possible specification, simulateneity and omitted variable bias.

Specification bias: occupational heterogeneity, trade and the gender wage gap

The impact of globalization on the gender gap may vary across occupations. First, the existing gap may vary across occupations, and globalization may be expected to have

17 See www.worldbank.org/research/trade. 
the greatest impact on those occupations with the largest gap (and potential for reduction). Second, occupations differ in terms of worker and sector characteristics and may therefore be impacted differently.

An especially important distinction is that between high versus low skill occupations. ${ }^{18}$ If the gender gap is primarily reduced through sector expansion (with increasing relative demand for female labor), then we would expect trade to have a negative impact on the low skill gender gap in poorer countries and the high skill gender gap in richer countries. This is because standard trade theory suggests that low skill occupations are most likely to benefit from trade expansion in poorer countries and the high skill occupations in richer countries. Conversely, if the gender gap is primarily reduced through sector contraction (with increasing competition from imports), then we expect a large impact on the high skill gender gap in the poorer countries and the low skill occupations in the richer countries. Hence standard trade theory suggests that trade may have different impacts on the gender gap depending on the income (or average skill) level of the country and the skill type of the occupation. For this reason it is important to distinguish between these skill types.

Because we lack independent information on the skill or educational levels within each occupation, we define high skill occupations as those occupations that are within the top half of the occupational wage distribution within a country. Low skill occupations are defined as those occupations in the bottom half of the wage distribution. ${ }^{19}$ This procedure to distinguish between low and high skill occupations is reasonable given that wage levels and skills tend to be strongly correlated.

In Table 5 we report cross-section estimates for the occupational gender wage on skill type. The inclusion of year dummies subsumes any time pattern as we are focusing on the cross-sectional relationship between skill type and gender gap.

18 We are grateful to Aart Kraay for pointing this out.

19 The occupational wage distribution within a country is calculated as follows. First, we regress wages on dummies for pay, averaging, and period concepts as well as country by year dummies. Second, we calculate a standardized wage by subtracting the estimated coefficients from the observed wage. Unlike the standardization procedure as discussed before, we also subtract the coefficients for the country by year dummies to control for inflation and aggregate wage changes across years. Third, we take the average standardized wage across years for each occupation within a country to derive the occupational wage distribution for each country. 
Column 1 in Table 5 shows that the occupational gender wage gap is $8 \%$ point lower for low skill occupations in low and lower middle income countries compared to the high skill occupations. ${ }^{20}$ Column 2 shows that for the high and higher middle income countries the gender wage gap is $2 \%$ point lower for low skill occupations. Given that the lower skill occupations in poorer countries already have a $8 \%$ point lower gap than the high skill occupations the impact from sector expansion on the gender gap is expected to be moderate in the poorer countries.

In Table 6 we reestimate the regressions of Table 4 but now with interaction terms for the trade and FDI variables with the level of skill of the occupation. We have the following findings. First, the puzzling findings on the impact of GDP per capita on the gender gap as found earlier in Table 4 remain. Second, there is a generally significant negative impact of trade and FDI net inflows on the gender wage gap for low skill occupations, both in the poorer and richer countries. Third, there is a negative impact of trade on the gender wage gap for high skill occupations in richer countries, but not in poorer countries. Fourth, there is a positive (that is, widening) impact of FDI net inflows on the gender gap for high skill occupations in poorer countries. ${ }^{21}$

The above findings suggest that trade and FDI do not lower the gender wage gap for high skill occupations in poorer countries, which tend to have a $8 \%$ point higher gender gap (Table 5). According to standard trade theory, sectors intensive in scare factors will contract and the demand for scarce factors will fall. Hence, we would expect high skill occupations in poorer countries to suffer from increased import penetration and competition, and therefore falling gender gaps following Becker (1971). However, no such fall is observed.

How can we explain this surprising finding? From earlier research we know that high skill occupations in poorer countries often do not lose from globalization as there are many instances where the skill premium has increased with trade liberalization (Robbins 1997, Hanson and Harrison 1999, Robbins and Gindling 1999, Beyer, Rojas and Vergara 1999, Arbache, Dickerson and Green 2003, Hanson 2003). This may be due to the fact that high skilled labor is a complement for trade in low skill goods. Similarly the

20 The standard errors are corrected for clustering within the same country/occupation observations. 21 The positive and significant coefficients of the sectoral trade variable and the FDI variable for high skill occupations in richer countries is due to simultaneity bias (see Table 7). 
technology embodied in direct foreign investment and skilled labor may be complements. Trade and foreign investment can therefore significantly raise the demand for skilled workers, such as engineers, accountants, and finance specialists, and an increase in trade and foreign investment does therefore not necessarily lead to increased competitive pressures for high skill occupations in poorer countries.

However, we not only find an absence of a negative (and narrowing) impact, but a significantly positive (and widening) impact of FDI net inflows on the gender wage gap for high skilled occupations. ${ }^{22}$ This result is difficult to understand, unless there are significant gender gaps in human capital within high skill occupations in poorer countries (as suggested by the large difference in gender gap between low and high skill occupations in poorer countries in Table 5). In that case an FDI-induced increased demand for the better-qualified high-skill workers may disproportionally benefit male workers and lead to a larger gender wage gap. In other words, FDI benefits male engineers or computer programmers more than female engineers or computer programmers because they tend to be relatively better educated. ${ }^{23}$

The estimated coefficients for the aggregate trade variables (as a percentage of GDP, in current price or constant price) for the low skill occupations in poorer and richer countries are approximately -0.001 . This magnitude suggests that if trade increases with $10 \%$ point, that the gender gap would become $1 \%$ point lower. Given that the average occupational gender gap is $11 \%$ point, this reduction is substantial.

22 Earlier we noted that using country-specific adjustment factors in the standardization procedure gives virtually the same results (footnote 11). There is one notable difference, however, namely that the estimated coefficients of the trade measures for the high skill occupational gender gap in poorer countries become larger and even significantly positive for two of the three measures. This may even suggest the occupational gender wage gap also increases with trade for high skill occupations in poorer countries. 23 Note that this argument implicitly assumes that gender differentials in human capital are relatively less important for low skill occupations as well as for high skill occupations in richer countries. This is plausible because (a) human capital differentials are more likely to show up in high skill occupations creating larger occupational gender wage gaps in high skill occupations (see Table 5), and (b) female education lags behind male education in economic development (see Filmer 1999). 


\section{Simultaneity bias}

So far we have looked at the impact of trade and FDI net inflows on the gender wage gap. It is possible that the above estimates suffer from a simultaneity bias, however, with the gender wage gap affecting trade and FDI net inflows. A high gender wage gap

may reflect low female wages, and potential cost-savings if exports are 'female-led' (see Rodrik 2000, Seguino 2002, Kucera 2002, Busse 2003). Also a high gender wage gap may reflect discrimination and inefficiency in an imperfectly competitive environment, affecting the incentives for trade and investment.

The issue of simultaneity bias has received much attention within the related literature on the impact of openness on income and economic growth. Several studies have shown that increased openness leads to economic growth (Sachs and Warner 1995, Edwards 1998, Frankel and Romer 1999, Dollar and Kraay 2001), but others have suggested that economic growth and trade are primarily determined by geography and institutions instead (Diamond 1997, Gallup, Sachs and Mellinger 1998, Hall and Jones 1999, Sachs 2001, Acemoglu, Johnson and Robinson 2001, Rodrik, Subramanian and Trebbi 2002). Much in this debate therefore hinges on the ability to establish a causal relationship between openness and income and economic growth, and in particular in finding plausible instruments to control for endogeneity. In principle trade policy variables such as tariffs and non-tariff barriers are good instruments except that trade outcomes and trade policy variables are extremely weakly correlated (see Dollar and Kraay 2001). As an alternative, Frankel and Romer (1999) have constructed measures of the geographic component of countries' trade, and used those measures to obtain instrumental variables estimates of the effect of trade on income. They argue that this a valid instrument because the geographic component of trade is truly exogenous. Potentially there are two limitations to this strategy. First, as noted by Rodriguez and Rodrik (2001), geography may be a determinant of income through many more channels than just trade. Second, the Frankel-Romer instruments are time-invariant, and can only be used to control for simultaneity bias in cross-section regressions. 
In spite of these caveats, we also use the Frankel-Romer instruments, as they will go a long way in reducing the simultaneity bias. ${ }^{24}$ In particular we interact the FrankelRomer instruments with the skill level of the occupation and use them as instruments for our trade and FDI measures. Table 7 reports the results of this exercise. Generally speaking the earlier results from Table 6 remain valid. We still find a negative impact of trade and FDI net inflows on the gender wage gap for low skill occupations, both in the poorer and richer countries. ${ }^{25}$ Also the earlier finding that there is a negative impact of trade on the gender wage gap for high skill occupations in richer countries is confirmed. In particular the coefficient for the sectoral trade variable is now also negative (although insignificant), confirming that simultaneity bias is especially important for the sectoral trade data, presumably because high gender gaps imply cost-savings and increase trade intensity with an upward bias in the OLS estimate. Interestingly, however, the significant positive impact of FDI on high skill occupations in Table 6 becomes now significantly negative for richer countries. Hence, FDI may still increase the gender wage gap, but only for high skill occupations in poorer countries. This finding is consistent with the earlier explanation that high skill occupations may be complementary to trade in low skill goods in developing countries.

Also the estimated coefficients for the trade and FDI variables are generally larger when instrumented (compare Tables 6 and 7). This result may reflect the attenuation bias because of measurement error in Table 6, as well as simultaneity bias. ${ }^{26}$ In the poorer countries a $10 \%$ point increase in trade (as a $\%$ of GDP) lowers the low skill gender gap by $1 \%$ point. In richer countries a similar increase in trade intensity would reduce the gender gap by $2 \%$ point, both in low and high skill occupations. The impact of FDI on the gender gap is particularly large - a 1\% point increase in FDI (as a \% of GDP) would lower the gender gap by 3-4\% points, except for the high skill occupations in poorer countries.

\footnotetext{
24 Dollar and Kraay (2001) have used lagged levels of trade as an instrument, assuming that any timevarying omitted variables are uncorrelated with lagged levels of openness. This strategy also has its limits because it does not take into account any serial correlation in growth (shocks).

25 There is a positive and insignificant coefficient on the sector trade variable only for low skilled occupations in poorer countries.

26 Simultaneity bias will lead to an upward bias if gender gaps imply cost-savings and therefore increase trade and FDI net inflows.
} 


\section{Omitted variable bias}

The above estimates may suffer from omitted variable bias if the occupational gender wage gap is affected by other factors other than economic development, trade and FDI net inflows. Here we will investigate two different types of omitted variable bias, namely omitted variable bias due to observed and omitted variable bias due to unobserved variables. With respect to the observed omitted variable bias we investigate three types of omitted variables, namely wage-setting institutions, intra-country trade, and occupational segregation and inequality. With respect to the unobserved omitted variable bias we will investigate the impact of omitted unobserved country and occupation characteristics.

\section{Wage-setting institutions}

The first type of observed factor we consider is the impact of wage-setting institutions. It has typically been found that pay differentials are reduced with strong institutional determination of wages and/or prices (Freeman and Oostendorp 2000). Here we test whether this is also the case for the wage differentials between female and male workers in the same occupations.

We have two types of measures of the role of institutions in wage-setting. First, we have obtained estimates of union density for a large number of countries in 1990-95 from Visser (1999); these numbers are subject to considerable measurement error. But perhaps the biggest problem with them is that union density does not necessarily translate into collective bargaining and wage determination. Some countries, such as the Netherlands or Austria have modest union density but near universal collective bargaining. Other countries, such as the Ukraine or China have high union density, but little or no collective bargaining. Accordingly, we use the union density figure from Visser except for OECD and (ex-)communist countries. For OECD countries, we have replaced unionism with OECD estimates of collective bargaining coverage from OECD (1997). For communist countries such as China and for ex-communist countries, where 
the union figures do not reflect free trade unions, we have coded unionism as zero. Our second type of data are subjective evaluations of the extent of institutional intervention in an economy taken from the Heritage Foundation's Index of Economic Freedom. We have taken as an indicator the score given the country in the extent of wage/price interventions in the economy. The score ranges from 1 to 5 , reflecting an increasing intensity of institutional intervention. We have taken these variables from the 1998 Index of Economic Freedom, because this gives us the maximum number of country coverage.

Columns 1 and 5 of Table 8 show that wage-setting institutions have a large impact on the gender wage gap in richer countries, but not in poorer countries. ${ }^{27}$ For richer countries it is estimated that an increase in union density of $10 \%$ points will decrease the gender wage gap by $0.5 \%$ point. An increase in the regulatory score from 1 to 2 would lower the gender wage gap by $5 \%$ point. Hence, relative to trade, the impact of wage-setting institutions is substantial.

We do not find any significant impact of wage-setting institutions on the gender wage gap for the poorer countries. This insignificance may reflect the fact that these institutions tend to be weaker and less binding because of weaker enforcement and the large size of the informal sector. Significantly, the coefficients for the trade intensity variable are relatively unaffected (compare with columns 1 and 5 in Table 6), suggesting that omitted variable bias is no problem.

\section{Intra-country trade}

The gender wage gap may not only be affected by international trade but also by within-country trade. Increases in international trade may reduce the gender wage gap because of an increase in the relative demand for female labor or a decrease in discriminatory practices. The same effects can be expected from increases in withincountry trade. Also large countries may have relatively low intensity of international trade but a high intensity of within-country trade. Frankel and Romer (1999) therefore include trade intensity as well as proxy measures for within-country trade in their

27 The reported results are for trade intensity (as a \% of GDP, current prices). Similar results hold if one uses one of the other trade variables or the FDI net inflow variable. 
regressions to estimate the impact of (international) trade on aggregate income. Without the inclusion of proxy measures for within-country trade the coefficient for international trade would be biased.

Frankel and Romer assume that within-country trade is a function of size, which they proxy by population and area, both in logs. In interpreting these proxies, they focus on the sum of the coefficients on log population and log area, as this reflects the impact of an increase in population and area together, with no change in population density (Frankel and Romer, 1999 p.382). Such a change clearly increases the scope for withincountry trade.

In columns 2 and 6 of Table 8 we report the results if these proxies for withincountry trade are included. The coefficients on the area and population variables are jointly insignificant for the poorer countries ${ }^{28}$, but significantly positive for the richer countries. This is a puzzling and difficult to explain result as it suggests that larger countries tend to have a larger occupational gender wage gap compared to smaller countries. Most importantly, however, the coefficients on trade intensity variable are relatively unaffected (compare with columns 1 and 5 in Table 6), suggesting that omitted variable bias is not a big problem. ${ }^{29}$

\section{Occupational segregation and inequality}

The gender wage gap is only one possible measure of inequity and may be related to other measures of inequity. Another dimension of gender inequity which is often analyzed is that of occupational segregation (see for instance Anker, 1998). The literature distinguishes between two different forms of occupational segregation by sex. Horizontal segregation refers to the distribution of men and women across occupations, for instance women work as salespersons and men as truck drivers. Vertical segregation refers to the distribution of men and women in the same occupation with one sex more likely to be at a higher grade or level. For instance men are more likely to be working at highly competitive firms and women working at less competitive firms.

28 The F-test on the joint significance of the population and area variables has a p-value of 0.12.

29 The reported results are for trade intensity (as a \% of GDP, current prices). Similar results hold if one uses one of the other trade variables or the FDI net inflow variable. 
Vertical segregation may be an explanation why women earn less than men even within the same occupation. Horizontal segregation may substitute for gender wage gaps as it may allow discriminatory employment practices without violating the widely accepted equal-pay-for-equal-work norm. Hence, horizontal and vertical integration should be taken into account when explaining gender wage gaps.

Horizontal occupational segregation is measured by the index of dissimilarity that is by far the most commonly used inequality index. It is defined as one-half of the summation over all occupations of the absolute differences between the proportion of all females and the proportion of all males in each occupation. It has a minimum value of 0 (no segregation) and a maximum value of 1 (complete segregation) (see Anker 1998, p.69). We use information on the number of female and male workers at the 3-digit ISIC level from the Trade and Production Database to calculate the index of dissimilarity. This index at the sector level is subsequently linked with the ILO October Inquiry at the occupational level given that each occupation belongs to a specific sector (ILO 1995).

It is more problematic to calculate a proxy for vertical segregation as this information is often unavailable at the country level, let alone for a large country dataset. We therefore use a rough proxy, namely the number of firms in a sector, assuming that vertical segregation is more likely as the sector expands with an increasing diversity of firms. Once again, we use information from the Trade and Production Database on the number of firms at the 3-digit ISIC level and link this information with the ILO October Inquiry at the occupational level.

Columns 3 and 7 show the results if we include our proxies for horizontal and vertical occupational segregation in the regression. The only significant effect is for the number of firms in richer countries - the occupational gender gap tends to be higher in countries with more firms in a sector. ${ }^{30}$ This finding confirms our hypothesis that an expansion of the number of firms may increase the opportunities for vertical segregation, and therefore contributes to the gender wage gap within occupations. However, the trade variables are all insignificant now, because of the stark reduction in sample size. If we rerun the same regression but without the segregation variables on the same smaller

30 No significant effect is found in poorer countries possibly because many firms are unregistered and informal firms. 
sample (not reported), then we find almost identical and insignificant coefficients for the trade intensity variable. Hence, we may conclude that the omission of proxies for horizontal and vertical occupational segregation does not lead to an important omitted variable bias.

We also investigated whether the gender wage gap is related to overall wage inequality. Blau and Kahn (2001) have shown that a large part of the cross-country differences in the gender wage gap can be explained by differences in wage inequality. ${ }^{31}$ This is because the pay of women tend to be at the bottom of the wage distribution so countries with a compressed wage structure will tend to have a lower gender wage gap.

If women tend to be at the bottom of the wage distribution within occupations, then we may also expect countries with a greater wage inequality to have a larger gender gap. However if the occupations are sufficiently narrowly defined, no such effect can be expected.

We have estimated whether empirically there is a relationship between wage inequality and gender wage gap. Wage inequality has been measured as occupational wage inequality, reflecting the wage structure. We have used the ILO October Inquiry to estimate the occupational wage inequality as the standard deviation of the log male occupational wage. ${ }^{32}$ Columns 4 and 8 of Table 8 show the regression results if this measure of wage inequality is included. Unlike Blau and Kahn, we do not find a significant (positive) relationship between wage inequality and the gender gap, suggesting that the occupations are sufficiently narrowly defined. Also the coefficients for the trade intensity variable are virtually unaffected implying the unimportance of omitted variable bias in this instance.

31 They also show that another large part can be explained by cross-country differences in female net supply. We have also calculated their measure of female net supply and found a weakly significant negative effect on the gender wage gap in richer countries (p-value 0.09). This may reflect a simultaneity bias, if higher gaps lead to less net supply because of low female wages. Importantly, the coefficient for the trade variable was not significantly affected.

32 We have estimated the occupational wage inequality for all country/year pairs for which at least 30 occupational wage observations were available (see Freeman and Oostendorp, 2002). 


\section{Unobserved country and occupation characteristics}

It is also possible that the results are biased because of the presence of unobserved country and/or occupation characteristics that are correlated with the regression variables. Also the dataset is highly unbalanced, in the sense that countries report gender gaps for different occupations in different years, and countries report often only for a subset of years. As a consequence the results may also suffer from a sample selection bias. We therefore also exploit the panel data structure of the ILO October Inquiry by including country by occupation dummies in the regressions (Table 9). The inclusion of these dummies implies that the impact of the trade and FDI variables is solely based on changes in trade and FDI intensity within a given occupation for a given country over time. Hence, the regressions are unaffected by time-invariant (observed and unobserved) country and occupation characteristics, and also controls (to some extent) for sample selection bias. The disadvantage of this procedure is, however, that the results become more sensitive to measurement error and therefore are more likely to suffer from attenuation bias.

Table 9 reports the results of the time-series analysis. First we simply estimate a linear trend on the occupational gender wage gap, and do find a negative trend (columns 1 and 6). The coefficients are imprecisely estimated, however, and only approaching 10\% significance for the richer countries ( $p$-value 0.14 ). A coefficient of -0.001 implies a $0.1 \%$ point narrowing of the occupational gender wage gap each year.

The positive coefficients for GDP per capita for poorer countries in the crosssection analysis (see Table 6) are no longer significant and even negative in three out of four cases, confirming the pattern observed in Figure 2. Also three of the coefficients for GDP per capita for richer countries (Table 6) become significantly negative after the inclusion of country by occupation dummies. Only if we use sectoral trade measures we still find positive coefficients on the GDP per capita variable, but they are insignificant. Therefore we conclude that the gender gap has a tendency to fall within a given country with economic development, as suggested by figure 2 .

In Table 8 we have included controls for wage-setting institutions, intra-country trade, horizontal and vertical occupational sex segregation and wage inequality, but the 
positive relationship found earlier in Table 6 (for poorer countries) still held even with the inclusion of these potentially omitted variables. This result suggests that other (omitted) country characteristics create the omitted variable bias, for instance gender culture and anti-discrimination legislation. ${ }^{33}$ However, because we have no proxies for these omitted factors we are not able to test this formally.

We still find that trade has a negative impact on the low skill gender gap for the poorer countries. For the richer countries we also find a significant negative effect for the sectoral trade intensity variable, but a significant positive effect for the aggregate trade intensity variables. However, the finding for the sectoral trade variable is most relevant in this respect, because it measures most directly the link between changes in trade and the gender gap within given occupations and countries. The impact of FDI net inflows is now found to be positive for low skill occupations in richer countries and insignificant otherwise, contradicting the results in Tables 6 and 7. Also here we are suspicious of these results given that we lack information on sectoral rather than aggregate FDI net inflows to measure the link between changes in FDI and the gender gap within given occupations and countries.

\section{Conclusion}

In this paper we have undertaken one of the first truly global studies of the effect of globalization on the gender wage gap. The study is based on the most far-ranging crosscountry survey of wages available, the ILO October Inquiry, allowing us to measure the gender wage gap within narrowly defined occupations. Assuming that skills are relatively homogenous within these narrowly defined occupations, the occupational gender wage gap provides a direct measure of gender differences in labor market treatment and therefore discrimination. The occupational gender wage gap appears to fall with increasing economic development and trade, but not always. The lack of evidence of a narrowing impact of trade and evidence of a widening impact of FDI net inflows on the high skill occupational gender gap in poorer countries show that globalization may not

33 Although table 9 includes country by occupation dummies, the positive correlation between GDP per capita and the gender gap is already reversed if only country dummies are included. 
lower and in some instances may increase gender gaps. This finding complements earlier studies documenting an increase in wage inequality after trade liberalization in a number of developing countries, possibly reflecting skill complementarities.

We also found that labor market institutions have a major impact on occupational gender wage differentials, and may interfere with the impact of globalization on the gender gap. Unfortunately time-variant measures of labor market institutions are scarce, hampering our understanding of the mechanisms behind the changes in the occupational gender wage gap over time. Did labor market institutions change with changes in trade intensity, (partly) explaining the fall in the occupational gender wage gaps? With more information on the actual institutional functioning of the labor market, we may be better able to understand why trade may have lowered the occupational gender wage gap.

\section{References}

Acemoglu, D., S. Johnson and J. Robinson (2001): "The Colonial Origins of Comparative Development: An Empirical Investigation", American Economic Review, 91(5), pp.1369-1401.

Anker, R. (1998): Gender and jobs: sex segregation of occupations in the world. Geneva: ILO.

Arbache, J., A. Dickerson and F. Green, F (2003): "Trade Liberalisation and Wages in Developing Countries", Working Paper.

Artecona, R. and W. Cunningham (2002): "Effects of Trade Liberalization on the Gender Wage Gap in Mexico", The World Bank

Becker, G. (1971): The Economics of Discrimination. $2^{\text {nd }}$ ed. Chicago: University of Chicago Press.

Beyer, H., P. Rojas and R. Vergara (1999): “Trade Liberalization and Wage Inequality”, Journal of Development Economics, 59(1), pp. 103-23.

Berik, G., Y. Rodgers, and J. Zveglich Jr. (2004): "International Trade and Gender Wage Discrimination. Evidence from East Asia", forthcoming in Review of Development Economics.

Black, S. and E. Brainard (2002): "Importing Equality? The Impact of Globalization on Gender Discrimination”, NBER Working Paper 9110. 
Black, S. and P. Strahan (2001): "The Division of Spoils: Rent-Sharing and Discrimination in a Regulated Industry", American Economic Review, 91(4), pp. 814-31.

Blau, F. and L. Kahn (2001): "Understanding International Differences in the Gender Pay Gap", NBER Working Paper No. 8200.

Busse, M. and C. Speilmann (2003): “Gender Discrimination and the International Division of Labour"' HWWA Discussion Paper 245.

Cagatay, N. and G. Berik (1991): "Transition to export-led growth in Turkey: is there a feminization of employment", Capital and Class, vol.43.

Diamond, J. (1997): Guns, Germs, and Steel. New York: W.W. Norton \& Co.

Dollar, D. and Kraay, A. (2001): “Trade, Growth, and Poverty”. Working Paper, March, Development Research Group, The World Bank.

Edwards, S. (1998): “Openness, Productivity and Growth: What Do We Really Know?”, Economic Journal, 108, pp.383-98.

Filmer, D. (1999): "The Structure of Social Disparities in Education: Gender and Wealth", Policy Research Report on Gender and Development, Working Paper Series No.5.

Fontana, M. and A. Wood (2000): "Modeling the Effects of Trade on Women, at Work and at Home", World Development, 28(7), pp.1173-90.

Freeman, R. and R. Oostendorp (2000): "Wages Around the World: Pay Across Occupations and Countries”. NBER Working Paper Series, 8058.

Freeman, R. and Oostendorp (2002): "The Occupational Wages around the World Data file", International Labour Review, 140(4).

Gallup, J., J. Sachs, and A. Mellinger (1998): Geography and Economic Development”, NBER Working Paper 6849.

García-Cuéllar, R. (2000): "Is Trade Good for Women? Evidence for the Lower-Skilled in Pre- and Post-NAFTA Mexico", chapter 1 in PhD Dissertation, Harvard University.

Grown, C., D. Elson and N. Cagatay (2000): “Introduction”, World Development, 28(7), pp.1145-56.

Hall, R. and C. Jones (1999): "Why Do Some Countries Produce So Much More Output 
per Worker than Others?", Quarterly Journal of Economics, 114(1), pp.83-116.

Hanson, G. (2003): "What Has Happened to Wages in Mexico since NAFTA? Implications for Hemispheric Free Trade", NBER Working Paper 9563.

Hanson, G. and A. Harrison (1999): "Trade liberalization and wage inequality in Mexico Industrial", Labor Relations Review, 52(2), pp. 271-88.

Hellerstein, J., D. Neumark, and K. Troske (2002): "Market Forces and Sex Discrimination", Journal of Human Resources, 37(2, pp:353-80.

ILO (1995): "ILO October Inquiry. Wages and Hours of Work. Descriptions of the Occupations. Annex 1".

Joekes, S. (1995): “Trade-Related Employment for Women in Industry and Services in Developing Countries", UNRISD, Occasional paper No.5.

Kucera, D. (2002): "Core Labour Standards and Foreign Direct Investment", International Labour Review, vol. 141, no.1/2, pp.31-69.

OECD (1997): Employment Outlook, July (Paris: OECD).

Ozler, S. (2000): "Export Orientation and Female Share of Employment: Evidence from Turkey”, World Development, 28(7), pp.1239-48.

Robbins, D. (1997): “Trade and Wages in Colombia”, Estudios de Economía, 24(1), pp.47-83.

Robbins, D. and T. Gindling (1999): "Trade Liberalization and the Relative Wages for More-Skilled Workers in Costa Rica", Review of Development Economics, 3(2), pp.140-54.

Rodriguez, F. and D. Rodrik (2001): "Trade Policy and Economic Growth: A Skeptic's Guide to the Cross-National Evidence", in NBER Macroeconomics Annual 2000 (Ben Bernanke and Kenneth Rogoff, eds.), Cambridge MA: MIT Press for NBER. 
Rodrik, D. (2000): "Institutions for High-quality Growth: What They Are and How to Acquire Them", Studies in Comparative International Development, vol.35, no.3, pp.3-31.

Rodrik, D. (2002): "Institutions Rule: the Primacy of Institutions over Geography and Integration in Economic development”, NBER Working Paper 9305.

Sachs, J. (2001): “Tropical Underdevelopment”, NBER Working Paper 8119.

Sachs, J. and A. Warner (1995): "Economic Reform and the Process of Global Integration", Brookings Papers on Economic Activity, 1, pp.1-118.

Seguino, S. (2000): “Gender Inequality and Economic Growth: A Cross-Country Analysis", World Development, 28 (7), pp. 1211-1230.

Standing, G. (1999): “Global feminization through flexible labor: a theme revisited", World Development, 27(3), pp. 583-602.

Tzannatos, A. (1995): “Growth, Adjustment and the Labor Market: Effects on Women Workers". World Bank, Education and Social Policy Department.

Tzannatos, A. (1999): "Women and Labor Market Changes in the Global Economy: Growth Helps: Inequalities Hurt and Public Policy Matters", World Development, 27(3), pp.551-69.

Visser, Jelle (1999): "Global Trends in Unionisation: A Report to the ILO Task Force on Industrial Relations", mimeo. Cesar Department of Sociology, University of Amsterdam.

Wood, A. (1991): "North-South trade and female labour in manufacturing: An asymmetry", Journal of Development Studies, vol. 27, no.2.

United Nations (1999): 1999 World Survey on the Role of Women in development: Globalization, Gender, and Work. Report of the Secretary-General.

World Bank (2001): Engendering Development. Through Gender Equality in Rights, Resources, and Voice. World Bank Policy Research Report. New York: Oxford University Press. 
Table 1. Evolution of the ILO's October Inquiry

\begin{tabular}{lrrrr}
\hline & $\begin{array}{r}\text { Number of } \\
\text { occupations }\end{array}$ & $\begin{array}{c}\text { Number of countries reporting } \\
\text { In a given year }\end{array}$ & $\begin{array}{r}\text { Cumulative } \\
\text { reporting }\end{array}$ & $\begin{array}{r}\text { Gender breakdown } \\
\text { Number of } \\
\text { occupations }\end{array}$ \\
\hline 1924 & 18 & 15 & 15 & 0 \\
$1925-28$ & 18 & $16-19$ & 20 & 0 \\
1929 & 30 & 17 & 20 & 0 \\
$1930-50$ & 30 & $16-37$ & 69 & 0 \\
1951 & 41 & 19 & 69 & 0 \\
1952 & 41 & 48 & 77 & 0 \\
1953 & 48 & 47 & 82 & 6 \\
$1954-82$ & 48 & $54-103$ & 181 & $6-12$ \\
1983 & 161 & 56 & 181 & 108 \\
$1984-97$ & 161 & $58-76$ & 197 & $150-161$ \\
1998 & 161 & 53 & 197 & 161 \\
1999 & 161 & 45 & 197 & 153 \\
\hline
\end{tabular}

The October Inquiry results were published chronologically by the ILO as follows.

Data for 1924-45 International Labour Review (Geneva), Vols. 10 (No. 5, Nov. 1924) to 54 (No. 3 and 4, Sept.-Oct. 1946).

Data for 1934-57 Year Book of Labour Statistics, First Issue (Vol. II, 1934-35) to Eighteenth Issue (1958).

Data for 1951-63 International Labour Review (Geneva), separate monthly Statistical Supplement, Vols. 66 (July 1952 supplement) to 89 (July 1964 supplement).

Data for 1964-90 Bulletin of Labour Statistics (Geneva), relevant issues: second quarter in each year, 1965-85 (1984 results); separate annual edition, Bulletin of Labour Statistics: October Inquiry Results, 1985 (1983-84 results) to 1991 (1989-90 results).

Data for $1990+\quad$ Statistics on occupational wages and hours of work and on food prices, special supplement to the Bulletin of Labour Statistics, $1992+$.

Data for $1983+\quad$ Also available on-line on the ILO's website, at http://laborsta.ilo.org. 
TABLE 2: Observations with gender breakdown in the 1983-1999 October Inquiry Computer Files

A. SAMPLE SIZE

Maximum Conceivable Observations

$\mathbf{2 2 7 , 1 7 1}$

observations missing because country did not report in given year

80,500

observations missing because occupation missing in year country reported

133,651

Actual year/country/occupation observation

13,020

observations with multiple figures

5,860

multiple figures

5,911

Total, including all multiple observations

18,931

B. COUNTRIES AND OCCUPATIONS WITH AT LEAST ONE REPORTED GENDER BREAKDOWN

Countries With Reported Gender Breakdown for different numbers of occupations

\#s of occupation

$<5$

$5-9$

$10-24$

25-49

$50-74$

75-99

$100+$
\# of countries (total: 83 )

17

13

16

17

5

7

8

Occupations with one Reported Gender Breakdown for different numbers of countries

\#s of countries

reporting on occupation \# of occupations (total: 161)

$\begin{array}{lr}<10 & 23 \\ 10-19 & 72 \\ 20-29 & 48 \\ 30-39 & 16 \\ 40-49 & 2\end{array}$

Pay concept

C. ACTUAL OBSERVATIONS

Wages (70 countries)

9,532

Earnings (50 countries)

9,399

Averaging concept

Mean

17,407

Minimum

634

Maximum

138

Prevailing

173

Median

567

Other

12

Period concept

Monthly 12345

Hourly $^{34} 2822$

Weekly 3140

Daily 499

Annual 115

Fortnight 10

${ }^{34}$ The hourly figures include small number for whom the data tell us that they relate to hours paid for and another small number for whom the wages relate to hours worked. 
Table 3: Measures of the occupational wage gap within countries, 1983-99*

Occupational Gender Wage Gap

\section{High Income Countries}

No. occupations

$$
\begin{aligned}
& \text { AT - Austria } \\
& \text { AU - Australia } \\
& \text { CA - Canada } \\
& \text { DK - Denmark } \\
& \text { FI - Finland } \\
& \text { GB - United Kingdom } \\
& \text { HK - Hong Kong } \\
& \text { JP - Japan } \\
& \text { NO - Norway } \\
& \text { PT - Portugal } \\
& \text { SE - Sweden } \\
& \text { SG - Singapore } \\
& \text { US - United States }
\end{aligned}
$$

Average across countries

Upper Middle Income Countries

BR - Brazil

GA - Gabon

KR - Korea, Republic of

MX - Mexico

MU - Mauritius

PR - Puerto Rico

Average across countries

Lower Middle Income Countries

BO - Bolivia

$\mathrm{HN}$ - Honduras

LK - Sri Lanka

PE - Peru

$\mathrm{PH}$ - Phillipines

TR - Turkey

Average across countries

\section{Low Income Countries}

BF - Burkina Faso

BJ - Benin

GH - Ghana

LR - Liberia

ML - Mali

ZR - Zaire

Average across countries
Unadjusted

Adjusted

2
116

116

42

31

80

25

17

29

21

83

110

97

50

0.08

0.16

0.13

0.06

0.13

0.14

0.08

0.35

0.04

0.09

0.11

0.15

0.13

0.13

0.08

0.16

0.14

0.07

0.12

0.14

0.08

0.33

0.02

0.09

0.10

0.14

0.12

0.12

135

4

15

40

27

42

3

44

2

8

0.26

0.25

0.00

$-0.01$

0.33

0.33

0.13

0.13

0.10

0.09

0.04

0.05

0.14

0.14

$-0.07$

0.14

0.14

0.11

0.11

0.11

0.10

0.06

0.22

0.22

0.09

0.09

0.11

0.10

0.03

0.03

0.08

0.08

0.12

0.11

0.01

$-0.02$

$-0.10$

$-0.10$

0.04

0.03 


\section{Economies with Small Populations}

AG - Antigua and Barbuda

AN - Netherlands Antilles

AS - American Samoa

BB - Barbados

CY - Cyprus

GI - Gibraltar

GP - Guadeloupe

GQ - Guinea Ecuatorial

IM - Isle of Man

IS - Iceland

KM - Comoros

KN - St. Kitts and Nevis

LC - St. Lucia

LU - Luxembourg

MO - Macau

$-0.05$

$-0.10$

$\mathrm{SC}-$ Seychelles

0.12

0.12

SZ - Swaziland

0.03

0.03

VI - Virgin Islands (US)

0.02

0.02

Average across countries

Communist \& Ex-Communist

\section{Economies}

AZ - Azerbaijan

2

0.07

0.07

BY - Belarus

48

0.10

0.10

$\mathrm{CN}$ - China

64

0.07

0.06

CS - Czechoslovakia

0.12

0.10

CZ - Czech Republic

0.09

0.07

$\mathrm{EE}$ - Estonia

0.13

0.13

HU - Hungary

0.14

0.15

KG - Kyrgyzstan

$-0.03$

$-0.03$

LT - Lithuania

0.14

0.12

LV - Latvia

0.14

0.12

PL - Poland

0.12

0.10

RO - Romania

135

0.07

RU - Russian Federation

104

0.12

0.11

SI - Slovenia

19

0.06

0.04

SK - Slovakia

107

0.14

0.14

Average across countries

0.10

0.09

Average across all countries

0.11

0.11

*For each country the year is selected for which most occupational gender wage gaps were reported (at least two occupational gender wage gaps). 
Table 4: Cross-section regression estimates (OLS) of the effect of per capita income, trade, FDI net inflows on the occupational gender wage gap by country income (standard errors in parentheses)

\section{Log GDP per capita}

Trade $(\%$ GDP)

Trade (\% GDP, constant LCU)

Sector Trade (\% sector output)

FDI net inflows (\%GDP)

Year dummies

Occupation dummies

Dummies for

Cyprus, Japan and Korea

Dummy for (ex) Communist

Observations

\begin{tabular}{|c|c|c|c|}
\hline 1 & 2 & 3 & 4 \\
\hline \multicolumn{4}{|c|}{ Low and lower middle income countries } \\
\hline \multirow{8}{*}{$\begin{array}{c}0.04 \\
(0.01) \\
-0.0004 \\
0.0002)\end{array}$} & 0.03 & 0.07 & 0.02 \\
\hline & $(0.01)$ & $(0.05)$ & $(0.01)$ \\
\hline & & & \\
\hline & & & \\
\hline & -0.0003 & & \\
\hline & & -0.00003 & \\
\hline & & $(0.0001)$ & \\
\hline & & & -0.003 \\
\hline
\end{tabular}

Yes

Yes

N/A

Yes

2246

0.16

Adjusted R ${ }^{2}$

Note: standard errors are corrected for clustering within the same

Yes

Yes

Yes

N/A

N/A

Yes

Yes

Yes

334

0.13
Yes

Yes

N/A

Yes 2244
5

High and highe

$-0.01$

$(0.01)$

$-0.0004$

$(0.0001)$

$$
\begin{gathered}
-0.0005 \\
(0.0001)
\end{gathered}
$$

$-0.00002$

$(0.00004)$

0.001

(0.002)

Yes

Yes

Yes

Yes
7187

Yes
7187

0.56 
Table 5. Cross-section (OLS) regression estimates of gender wage gap by skill of occupation (standard errors in parentheses)

Low skill occupation

(omitted: high skill occupation)
1

Low and lower middle income countries

$-0.08$

$(0.01)$
2

High and higher middle income countries $-0.02$

$(0.01)$

Year dummies

$\begin{array}{cc}\text { Yes } & \text { Yes } \\ \text { Yes } & \text { Yes } \\ \text { Yes } & \text { Yes } \\ 2257 & 7666 \\ 0.03 & 0.40\end{array}$

Dummies for Cyprus, Japan and Korea

Dummy for (ex) Communist

Observations

Adjusted $\mathrm{R}^{2}$

0.03

0.40 
Table 6: Cross-section regression estimates (OLS) of the effect of per capita income, trade, FDI net inflows on the occupational gender wage gap by occupational skill level and country income (standard errors in parentheses)

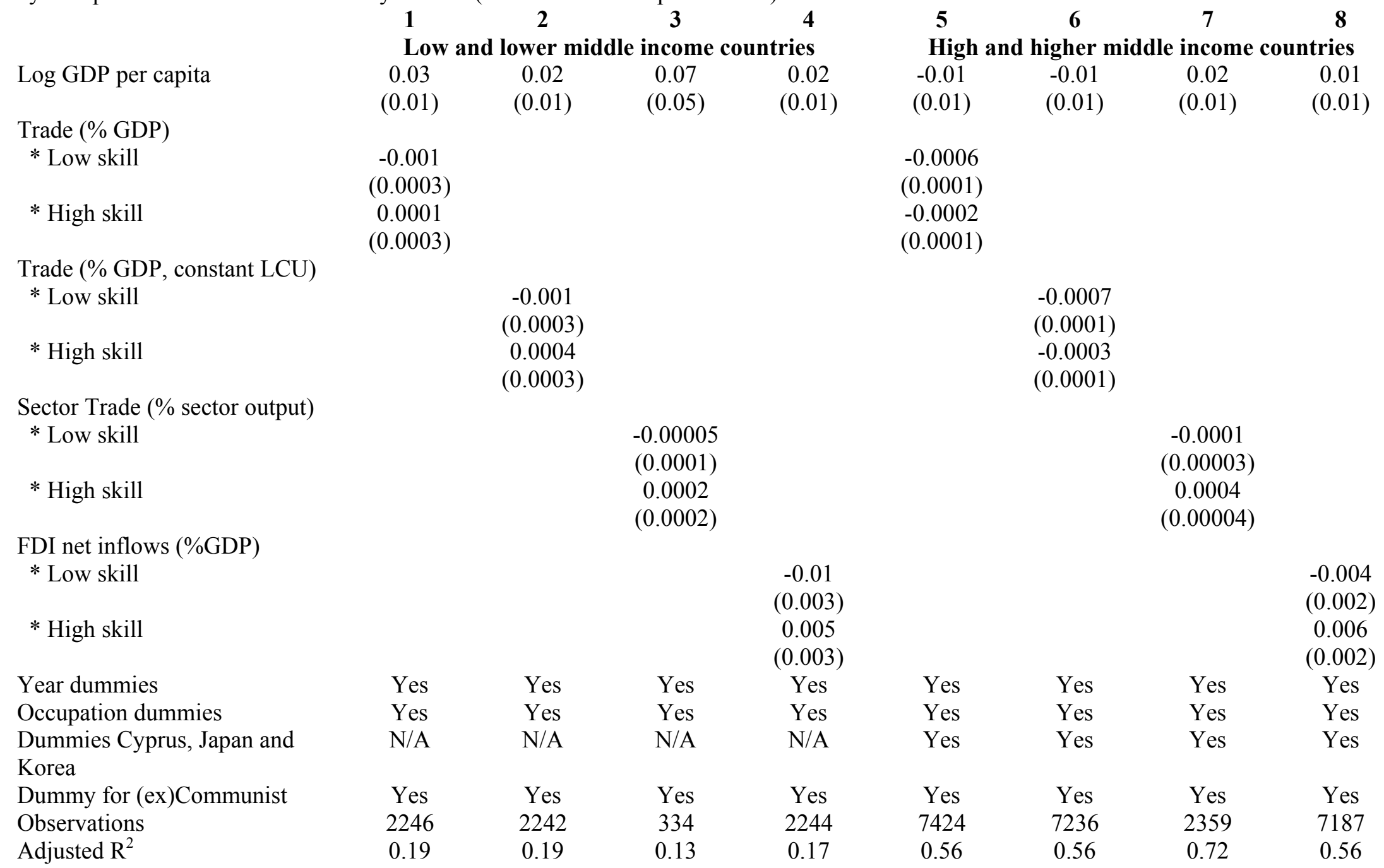

Note: standard errors are corrected for clustering within the same country/occupation observations. NA = not applicable. 
Table 7: Cross-section regression estimates (IV) of the effect of per capita income, trade, FDI net inflows on the occupational gender wage gap by occupational skill level and country income (standard errors in parentheses)

\begin{tabular}{|c|c|c|c|c|c|c|c|c|}
\hline & 1 & 2 & 3 & 4 & 5 & 6 & 7 & 8 \\
\hline & \multicolumn{4}{|c|}{ Low and lower middle income countries } & \multicolumn{4}{|c|}{ High and higher middle income countries } \\
\hline Log GDP per capita & $\begin{array}{c}0.02 \\
(0.02)\end{array}$ & $\begin{array}{c}0.02 \\
(0.02)\end{array}$ & $\begin{array}{c}0.10 \\
(0.07)\end{array}$ & $\begin{array}{c}0.02 \\
(0.02)\end{array}$ & $\begin{array}{l}-0.03 \\
(0.01)\end{array}$ & $\begin{array}{l}-0.03 \\
(0.01)\end{array}$ & $\begin{array}{c}0.01 \\
(0.02)\end{array}$ & $\begin{array}{l}-0.01 \\
(0.01)\end{array}$ \\
\hline \multicolumn{9}{|l|}{ Trade (\% GDP) } \\
\hline * Low skill & $\begin{array}{l}-0.001 \\
(0.001)\end{array}$ & & & & $\begin{array}{c}-0.002 \\
(0.0004)\end{array}$ & & & \\
\hline$*$ High skill & $\begin{array}{c}0.0005 \\
(0.0006)\end{array}$ & & & & $\begin{array}{c}-0.002 \\
(0.0004)\end{array}$ & & & \\
\hline \multicolumn{9}{|l|}{ Trade ( $\%$ GDP, constant LCU) } \\
\hline$*$ Low skill & & $\begin{array}{c}-0.001 \\
(0.0005)\end{array}$ & & & & $\begin{array}{c}-0.002 \\
(0.0004)\end{array}$ & & \\
\hline * High skill & & $\begin{array}{c}0.001 \\
(0.001)\end{array}$ & & & & $\begin{array}{c}-0.002 \\
(0.0003)\end{array}$ & & \\
\hline \multicolumn{9}{|l|}{ Sector Trade (\% sector output) } \\
\hline * Low skill & & & $\begin{array}{c}0.001 \\
(0.001)\end{array}$ & & & & $\begin{array}{c}-0.001 \\
(0.0005)\end{array}$ & \\
\hline * High skill & & & $\begin{array}{c}0.002 \\
(0.002)\end{array}$ & & & & $\begin{array}{l}-0.001 \\
(0.001)\end{array}$ & \\
\hline \multicolumn{9}{|l|}{ FDI net inflows ( $\%$ of GDP) } \\
\hline * Low skill & & & & $\begin{array}{l}-0.03 \\
(0.01)\end{array}$ & & & & $\begin{array}{l}-0.04 \\
(0.01)\end{array}$ \\
\hline$*$ High skill & & & & $\begin{array}{c}0.01 \\
(0.01)\end{array}$ & & & & $\begin{array}{l}-0.03 \\
(0.01)\end{array}$ \\
\hline Year dummies & Yes & Yes & Yes & Yes & Yes & Yes & Yes & Yes \\
\hline Occupation dummies & Yes & Yes & Yes & Yes & Yes & Yes & Yes & Yes \\
\hline $\begin{array}{l}\text { Dummies Cyprus, Japan and } \\
\text { Korea }\end{array}$ & N/A & $\mathrm{N} / \mathrm{A}$ & $\mathrm{N} / \mathrm{A}$ & $\mathrm{N} / \mathrm{A}$ & Yes & Yes & Yes & Yes \\
\hline Dummy for (ex)Communist & Yes & Yes & Yes & Yes & Yes & Yes & Yes & Yes \\
\hline Observations & 1766 & 1762 & 334 & 1764 & 7030 & 6842 & 2351 & 6903 \\
\hline Adjusted $\mathrm{R}^{2}$ & 0.27 & 0.27 & 0.12 & 0.25 & 0.60 & 0.61 & 0.45 & 0.54 \\
\hline
\end{tabular}


Table 8: Cross-section regression estimates (OLS) of the effect of per capita income, trade, FDI net inflows on the occupational gender wage gap by occupational skill level and country income with control variables (standard errors in parentheses)

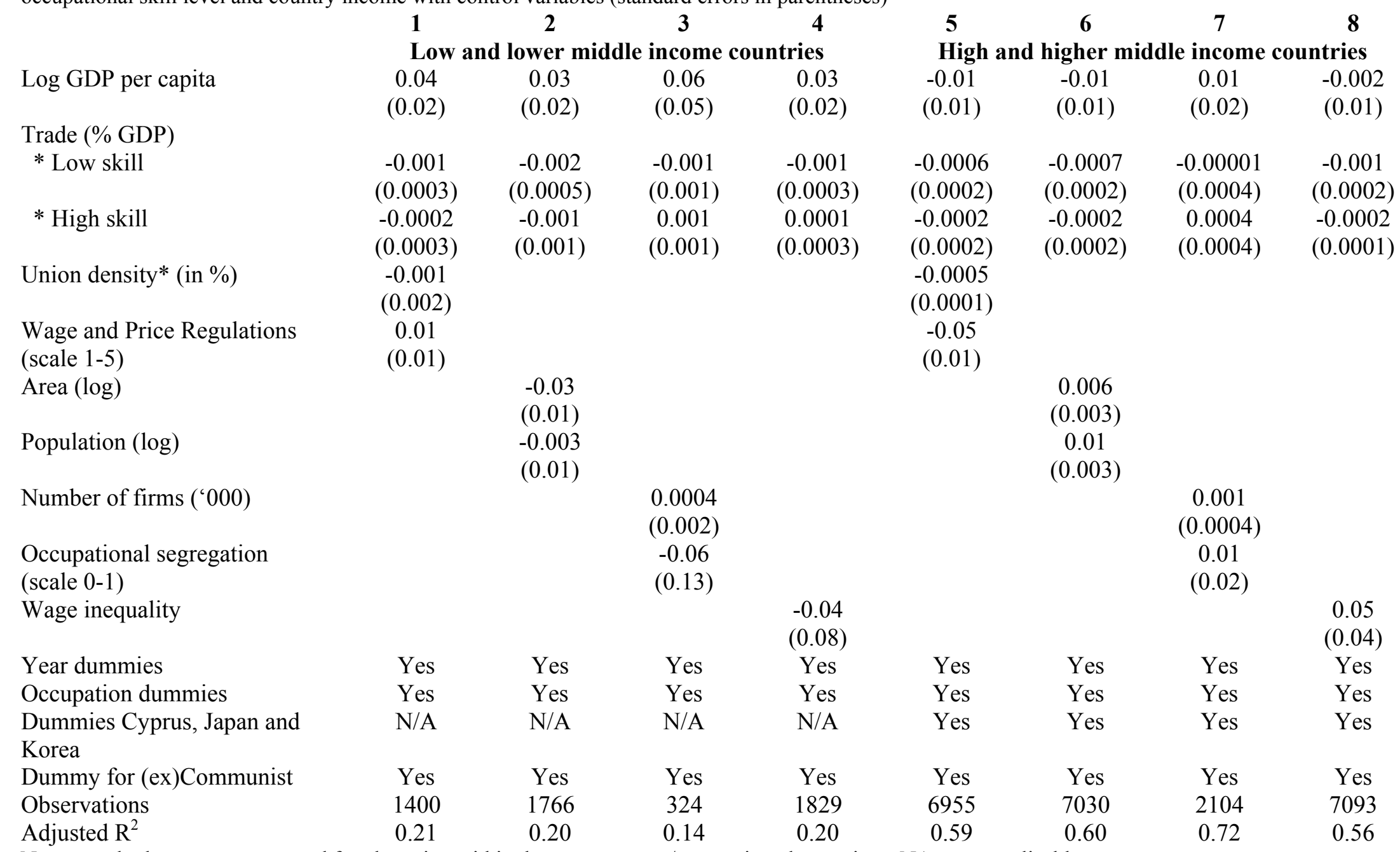

Note: standard errors are corrected for clustering within the same country/occupation observations. NA = not applicable.

*For OECD and (ex-)communist countries union density is replaced by collective bargaining coverage and zero respectively. 
Table 9: Time-series regression estimates (fixed effects) of the effect of per capita income, trade, FDI net inflows on the occupational gender wage gap by occupational skill level and country income (standard errors in parentheses)

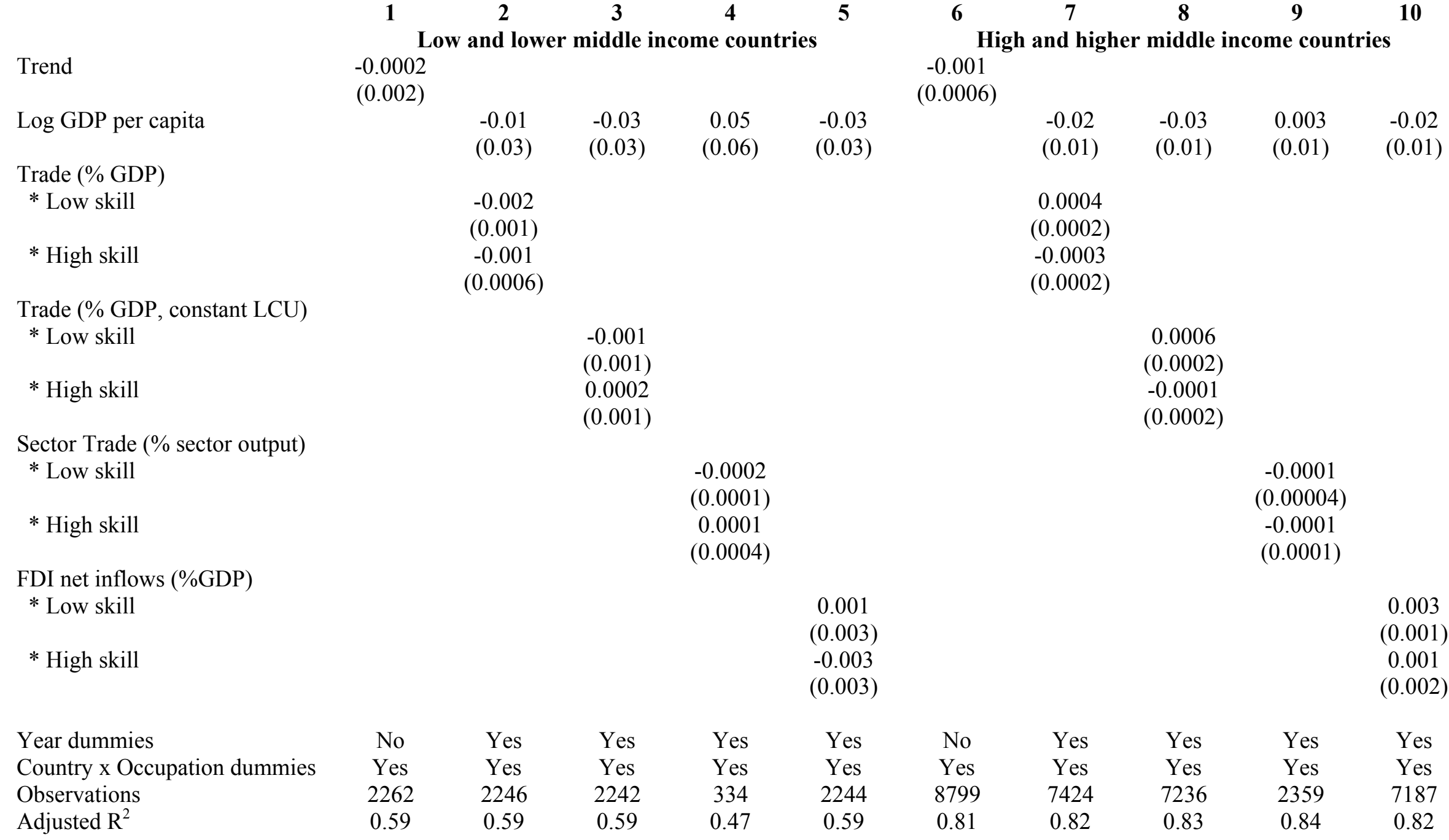


Figure 1: Occupational gender wage gap vs log GDP per capita, by country

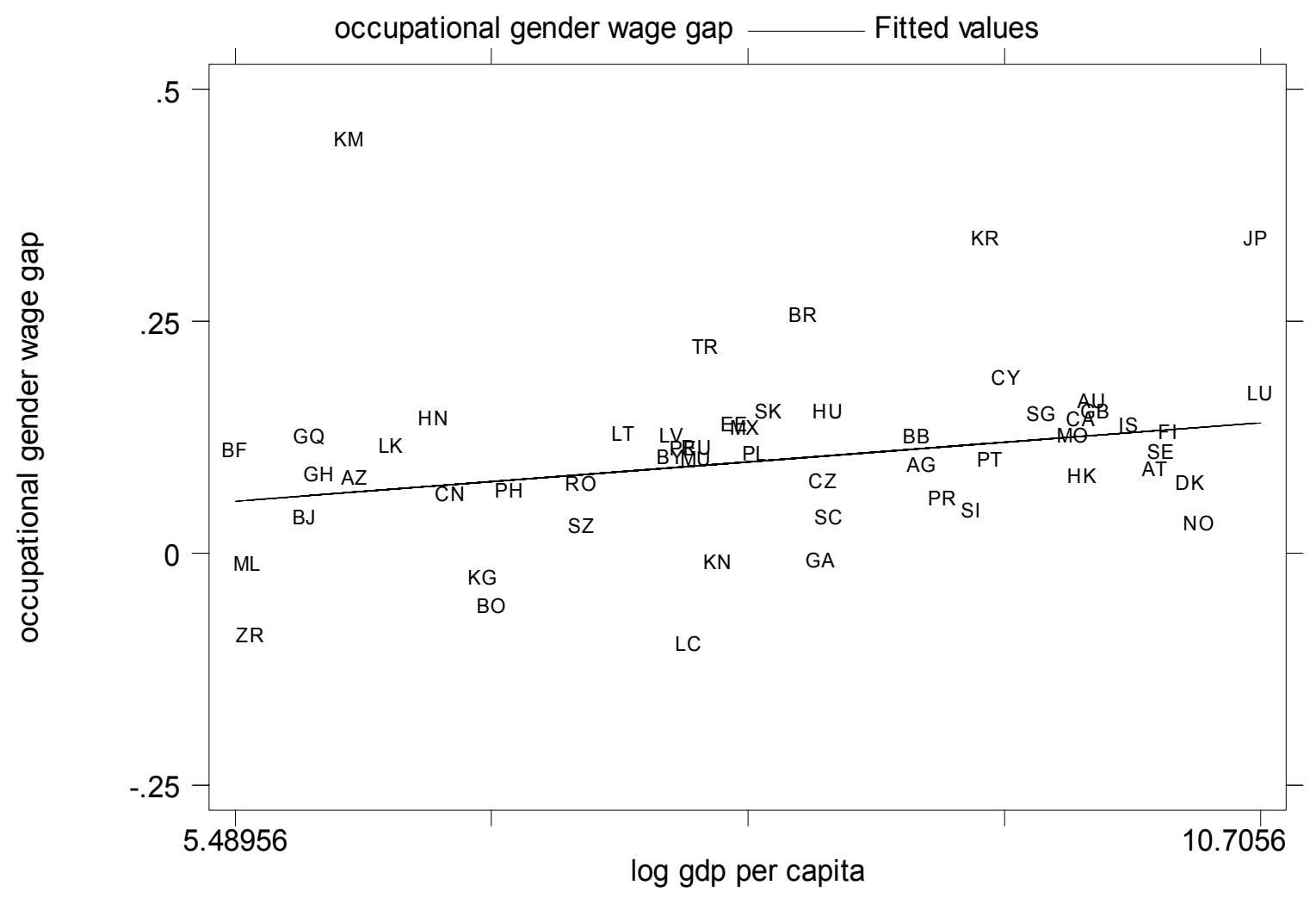

Country key:

AG-Antigua and Barbuda; AN-Netherlands Antilles; AS-American Samoa; AU-Australia; BJ-Benin; BO-Bolivia; BR-Brazil; BY-Belarus; CA-Canada; CN-China; CS-Czechoslavakia; CY-Cyprus; CZCzech Republic; DK-Denmark; EE-Estonia; FI-Finland; GA-Gabon; GB-United Kingdom; GHGhana; GI-Gibraltar; GP-Guadeloupe; HK-Hong Kong; HN-Honduras; HU-Hungary; IM-Isle of Man; IS-Iceland; JP-Japan; KG-Kyrgyzstan; KM-Comoros; KN-Saint Kitts and Nevis; KR-Korea, Republic of; LC-St.-Lucia; LT-Lithuania; LU-Luxembourg; LV-Latvia; MO-Macau; MU-Mauritius; NO-Norway; PE-Peru; PL-Poland; PR-Puerto Rico; PT-Portugal; RO-Romania; RU-Russian Federation; SC-Seychelles; SE-Sweden; SG-Singapore; SI-Slovenia; SK-Slovakia; SZ-Swaziland; TRTurkey; US-United States; VI-Virgin Island (US); ZR-Zaire. 
Figure 2: Number of countries experiencing an increase and decrease in occupational gender wage gap by GDP per capita growth

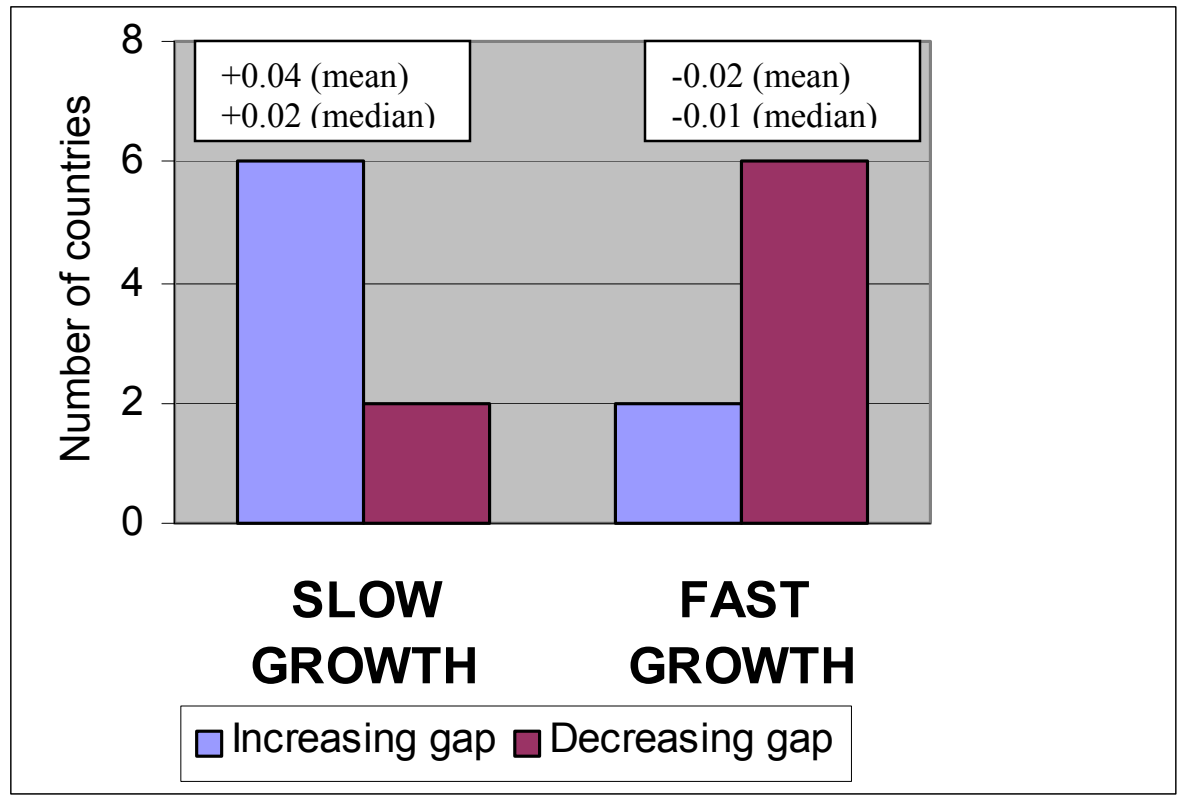

Countries included among slow growth group:

AU, DK, FI, GA, HN, IS, PE, SE

Countries included among fast growth group:

CY, HK, KR, LC, LK, MU, PT, SG 
Figure 3: Occupational gender wage gap vs trade (\% of GDP, current prices), by country

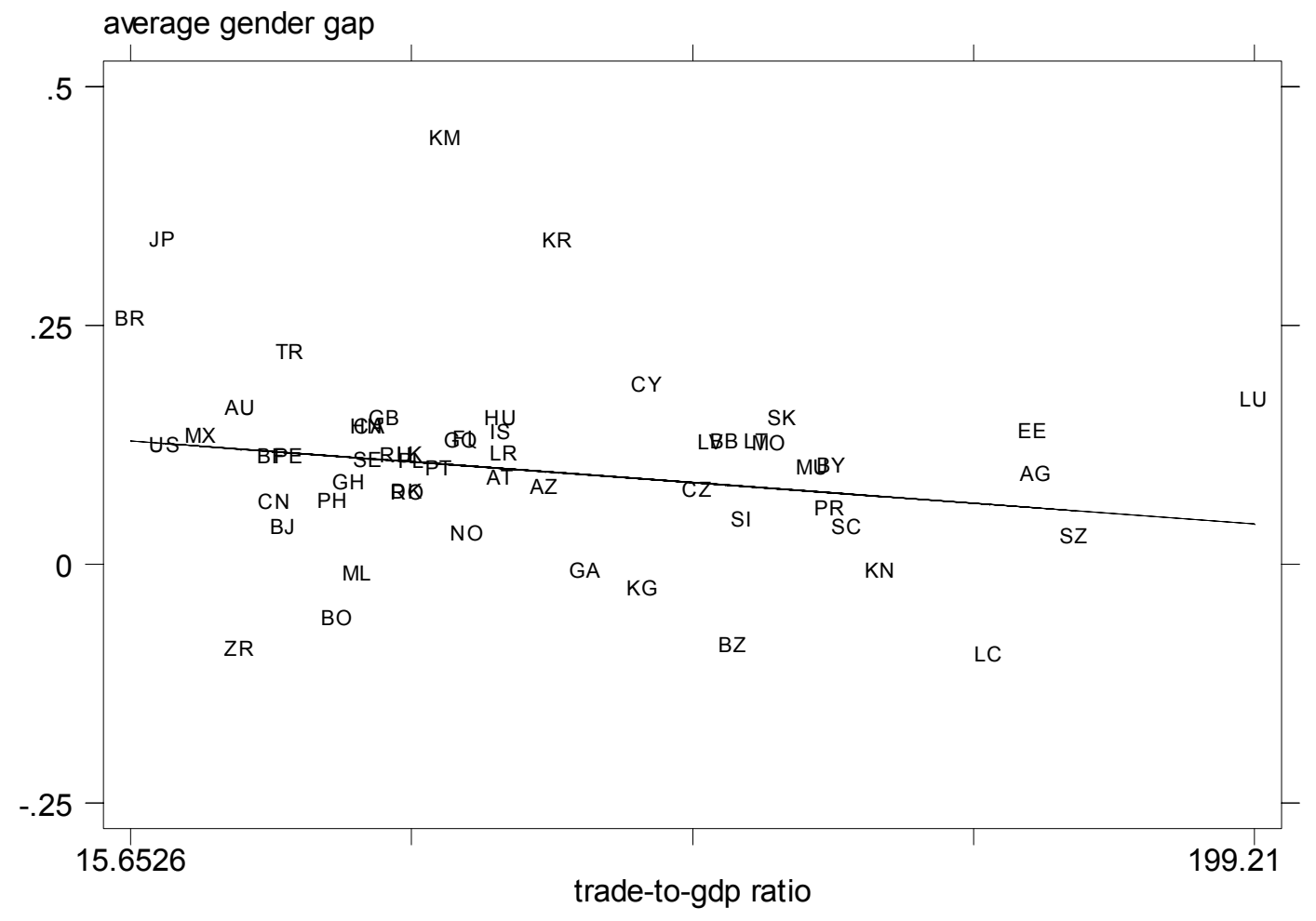


Figure 4: Occupational gender wage gap vs FDI net inflows ( $\%$ of GDP), by country

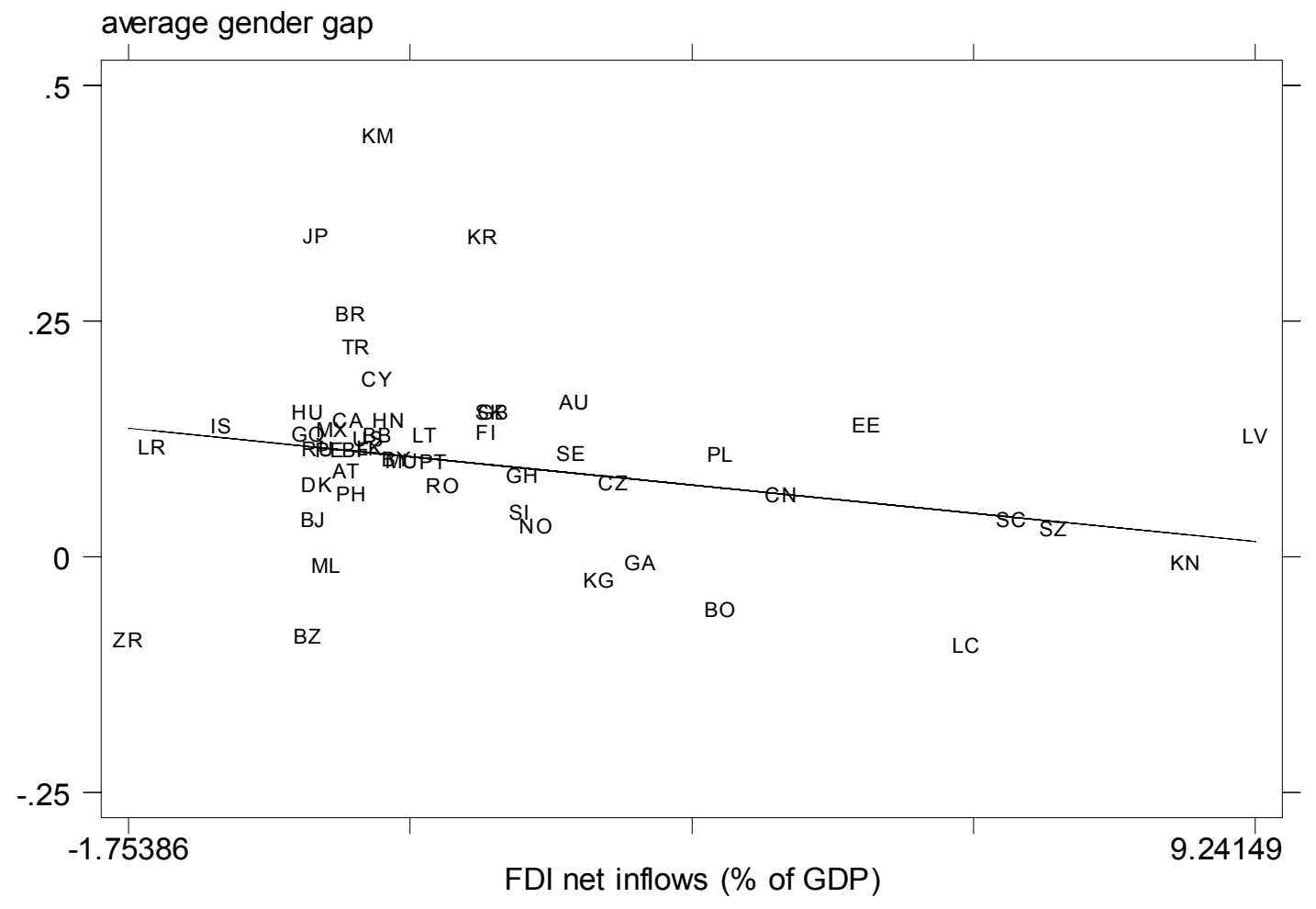


Figure 5: Number of countries experiencing an increase and decrease in occupational gender wage gap by trade growth

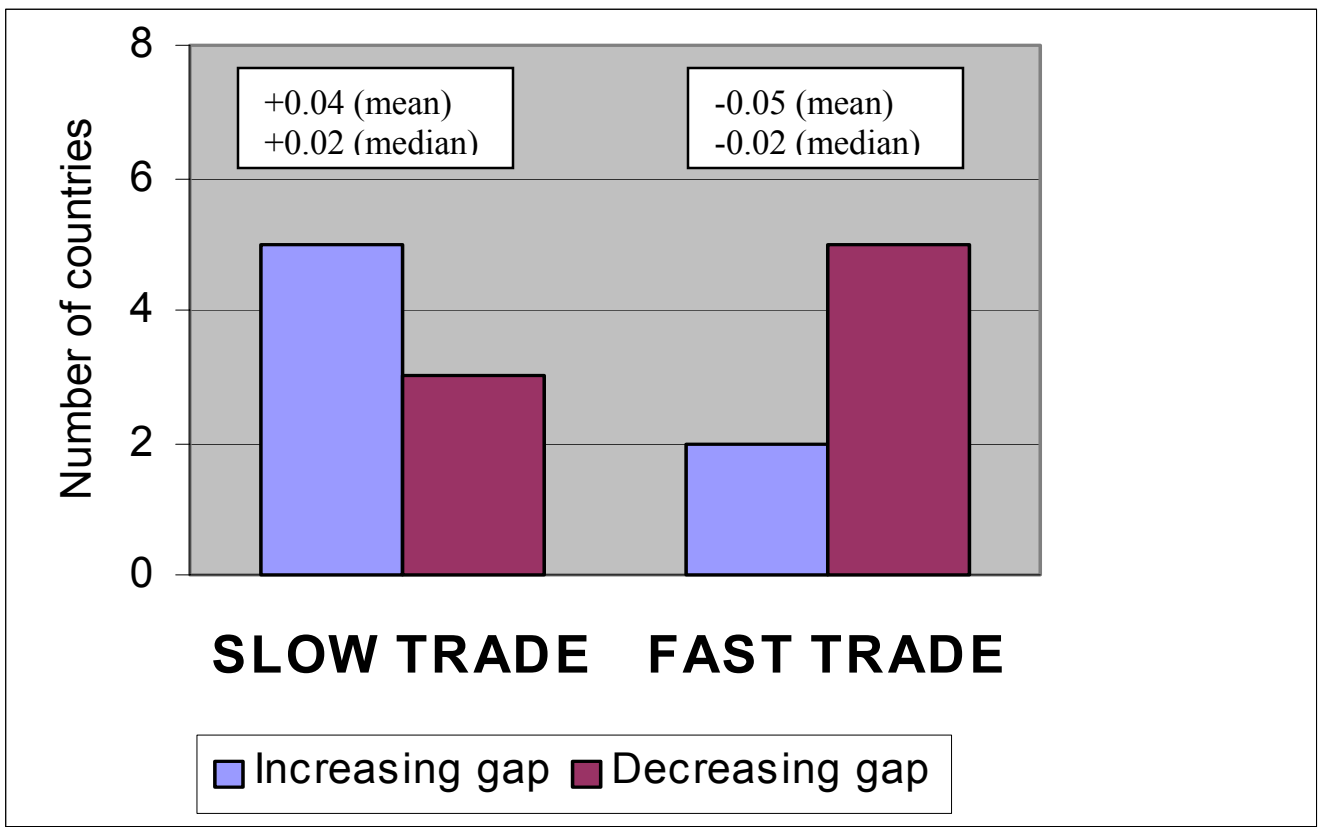

Countries included among slow trade group:

CY, GA, IS, JP, KR, PE, SE, SG

Countries included among fast trade group:

BO, FI, HK, HN, LK, MU, US 